\title{
Research Square \\ Removal of Cesium and Strontium From \\ Radioactive Wastewater by Prussian Blue Nanorods
}

\section{Chuqing Yao}

Nanjing University of Aeronautics and Astronautics

Yaodong Dai ( $\nabla$ yd_dai@sina.com )

Nanjing University of Aeronautics and Astronautics https://orcid.org/0000-0001-7965-5971

\section{Shuquan Chang}

Nanjing University of Aeronautics and Astronautics

Haiqian Zhang

Nanjing University of Aeronautics and Astronautics

\section{Research Article}

Keywords: Radioactive wastewater treatment, Prussian blue, Adsorption, Cesium, Strontium

Posted Date: January 3rd, 2022

DOI: https://doi.org/10.21203/rs.3.rs-1200891/v1

License: (c) (i) This work is licensed under a Creative Commons Attribution 4.0 International License. Read Full License 


\title{
Removal of Cesium and Strontium from radioactive wastewater by Prussian blue nanorods
}

Chuqing Yao, Yaodon Dai*, Shuquan Chang, Haiqian Zhang

College of material science and technology, Nanjing university of aeronautics and astronautics, Nanjing 211106, China

Corresponding author: yd dai@sina.com

\begin{abstract}
In this work, novel Prussian blue tetragonal nanorods were prepared by template-free solvothermal methods for removal of radionuclide Cs and Sr. It was worth that Prussian blue nanorods exhibited the better adsorption performance than co-precipitation PB or Prussian blue analogue composites. Thermodynamic analysis implied that adsorption process was spontaneous and endothermic which was described well with Langmuir isotherm and pseudo-second-order equation, the maximum adsorption capacity of PB nanorod was estimated to be $194.26 \mathrm{mg} \mathrm{g}^{-1}$ and $256.62 \mathrm{mg} \mathrm{g}^{-1}$ for $\mathrm{Cs}^{+}$and $\mathrm{Sr}^{2+}$. The adsorption mechanism of $\mathrm{Cs}^{+}$and $\mathrm{Sr}^{2+}$ was studied by X-ray photoelectron spectroscopy, $\mathrm{X}$-ray diffraction and ${ }^{57} \mathrm{Fe}$ Mössbaure spectroscopy, the results revealed that $\mathrm{Cs}^{+}$entered in $\mathrm{PB}$ crystal to generate a new phase, the most of $\mathrm{Sr}^{2+}$ was trapped in internal crystal and the other exchanged $\mathrm{Fe}^{2+}$. Furthermore, the effect of co-existing ions and $\mathrm{pH}$ for PB adsorption process were also investigated. The results suggest that PB nanorods were outstanding candidate for removal of $\mathrm{Cs}^{+}$and $\mathrm{Sr}^{2+}$ from radioactive wastewater.
\end{abstract}

Keywords: Radioactive wastewater treatment; Prussian blue; Adsorption; Cesium; Strontium

\section{Introduction}

With the rapid development of nuclear energy application in recent years, nuclear and radiation safety has aroused public attention. Decontaminating the large amount of radioactive waste water which generated in nuclear energy application has been become an urgent problem to be solved. Radiative strontium and cesium are the major contaminant in low-level radioactive waste water because of its seriously hazard to the natural environment and human health. How to remove these radionuclides efficiently 
from polluted water was the focus of research. Prussian blue $\left(\mathrm{Fe}_{4}\left[\mathrm{Fe}(\mathrm{CN})_{6}\right]_{3} \cdot \mathrm{xH}_{2} \mathrm{O}\right)$ was a kind of common adsorbent attract much attention because of their great adsorption capacity, good selectivity and low price[1]. The classic synthesis method of Prussian blue was potassium ferrocyanide and ferric chloride co-precipitated in aqueous solution, the obtained Prussian blue was agglomerated nanoparticle co-polymer which greatly reduced the number of adsorption sites. In recent, Prussian blue with particular shape has been prepared by diverse synthesis method, such as SeÂbastien Vaucher[2] synthesized superlattice Prussian blue nanocubes in reverse microemulsion, the length range of nanocube was $10 \mathrm{~nm}$ to $30 \mathrm{~nm}$. Lin $\mathrm{Hu}[3]$ prepared Prussian blue analogue porous nanocube in the presence of PVP, PBA nanocube present huge BET surface and excellent adsorption efficiency of $\mathrm{Pb}^{2+}\left(94 \%\right.$ in $\left.10 \mathrm{mg} \mathrm{L}^{-1}\right)$. $\mathrm{Bu}$ [4] used self-aggregation and orient attachment of Prussian blue particle synthesized three-dimensional hierarchical Prussian blue, the 3D Prussian blue shown the high adsorption capacity of $\mathrm{Cs}^{+}$which higher than commercial Prussian blue 95\%. Ming $\mathrm{Hu}[5,6]$ and Daoping Cai[7] used different method synthesized Prussian blue analogues cubes with hollow structure, the yolk-shell and yolk-double-shell PBA was obtained by hot hydrochloric acid etching in former research, the other one prepared $\mathrm{Ni}_{3}\left[\mathrm{Fe}(\mathrm{CN})_{6}\right]_{2}$ box and cube-inbox by chemical transformation method which was based on the different solubility of PBA in alkaline solution.

Compared with other structure of Prussian blue, the one-dimensional structured was usually ignored in research. 1D nanomaterials have received much attention due to their unique morphology and great potential applications[8]. 1D inorganic nanomaterials shown excellent adsorption capacity because of it had larger surface area and more adsorption site. Among the variety morphology of Prussia blue, one-dimensional structured PB was difficult synthesized owing to its complex elemental constituent and crystal structure. The research of 1D Prussian blue was less and the main synthesis route was sacrificial template method. Zhou et al[9]. fabricated Prussian blue nanotubes and nanowires by electrodeposition on porous anodic aluminum oxide, the size of Prussian blue depend on the diameter of pores, the obtained PB nanowires with diameters of 50 $\mathrm{nm}$ and length up to $4 \mu \mathrm{m}$. Xuemin Yin $[10]$ synthesized $\mathrm{Co}_{3}\left[\mathrm{Fe}(\mathrm{CN})_{6}\right]_{2}$ hollow structure 
with prism, polyhedron, sphere morphology by using Cobalt acetate hydroxide, ZIF-67 and Co-glycerate precursor as template, respectively. It was noticeable that above methods were difficult to be applied in large scale wastewater decontamination due to their high cost and low output. On the contrary, hydrothermal was easier operated and cost less in commonly nanomaterial synthesis method, the final products had uniform morphology and high purity. Hydrothermal reaction utilized water under elevated pressures and temperatures above its critical point to increase the solubility of a solid and to speed up dissolution and recrystallization of precursor. Reverse microemulsion (water in oil) system was widely applied in synthesize nanomaterials[11], microemulsion contained aqueous phase which dispersed in oil phase and packaged by surfactant, aqueous phase provided an excellent react place for form specific shape. Microemulsion hydrothermal could effectively controlled the products morphology by adjusted the ratio of water, oil and surfactant.

In this work, we successfully synthesized the tetragonal Prussian blue nanorod by microemulsion solvothermal method. The morphology, structure and influence factor in growth process of PB nanorod were investigated. The obtained PB nanorod was utilized for removal of Strontium and Cesium in simulate radioactive wastewater, the adsorption performance was tested at different contact time, initial concentration, temperature, $\mathrm{pH}$ and co-existing cations.

\section{Experiment and characterization}

\section{Preparation of materials}

All chemicals were purchased from Aladdin and without further purification. Prussian blue nanorods were synthesized by hydrothermal microemulsion method. In a typical experiment procedure, $0.405 \mathrm{mmol}$ potassium ferricyanide and glucose dissolved in $4.05 \mathrm{ml}$ deionized water, $15 \mathrm{mmol} \mathrm{CTAB}$ and $65 \mathrm{mmol} \mathrm{n}$-pentanol add into $70 \mathrm{ml} \mathrm{n}$-hexane, then mixed two solution and keep stirred until microemulsion was optically transparent, after that, transferred microemulsion to $100 \mathrm{ml}$ stainless Teflonlined autoclave and maintained at $120^{\circ} \mathrm{C}$ for $12 \mathrm{~h}$, the stainless Teflon-lined autoclave cooled at room temperature. Finally, the precipitate was separated by centrifugation and 
washed with chloroform and ethanol mixture solution several times. The final products were drying in vacuum oven at $70^{\circ} \mathrm{C}$ for 12 hours. In order to investigated influence of surfactant on Prussian blue morphology and micelle size, we synthesized Prussian blue in $7.5,10,17.5,20 \mathrm{mmol} \mathrm{CTAB}$ and other condition not changed.

\section{Materials characterization}

Fourier Transform Infrared Spectroscopic (FTIR) spectra were recorded on Nicolet NEXUS870 FTIR spectrometer. Using the transition mode and the wavelength range set from 4000 to $500 \mathrm{~cm}^{-1}$. The morphology images of Prussian blue nanorod were acquired with FEI Quanta650 scanning electron microscopy. The crystal structure and select aera electron diffraction (SAED) of Prussian blue nanorod were obtained by FEI Tecnai G20 high resolution transmission electron microscopy. Thermogravimetric Analysis (TG) was used TGA5500 from 30 to $800^{\circ} \mathrm{C}$ in air. $77 \mathrm{~K} \mathrm{~N} \mathrm{~N}_{2}$ adsorptiondesorption isotherms measured by Micromeritics ASAP2460. Powder X-ray diffraction (XRD) patterns were measured by Rigaku Ultimate IV diffractometer using $\mathrm{Cu} \mathrm{k} \alpha$ radiation from $5-90^{\circ}$. The X-ray photoelectron spectrum (XPS) of Prussian nanorods before and after adsorption were measured on Thermo ESCALAB 250XI instrument. The high-resolution spectra were collected and calibrated to the binding energy of C 1s at $284.8 \mathrm{eV}$. Mössbauer spectrum was recorded using WSSL-10 spectrometer at $300 \mathrm{~K}$ and the $\gamma$-ray radioactive source was ${ }^{57} \mathrm{Co} / \mathrm{Rh}$.

\section{Adsorption procedure}

The Prussian blue nanorod was tested for the adsorption of radioactive ${ }^{90} \mathrm{Sr}$ and ${ }^{137} \mathrm{Cs}$ from aqueous solutions at room temperature using the batch technique. The radioactive wastewater contained ${ }^{90} \mathrm{Sr}$ and ${ }^{137} \mathrm{Cs}$ was simulated by $\mathrm{Sr}\left(\mathrm{NO}_{3}\right)_{2}$ and $\mathrm{CsCl}$ aqueous solution. $10 \mathrm{mg}$ sample was added in test tubes which contained $10 \mathrm{~mL}$ strontium nitrate solution. Then the tubes were shaken on a vortex shaker for specific time. The effect of several variables of solution $\mathrm{pH}$, react time, solution temperature, initial concentration was also studied. The $\mathrm{pH}$ value of solution was adjusted by adding $0.01 \mathrm{M} \mathrm{HCl}$ and $0.01 \mathrm{M} \mathrm{NaOH}$. At the end of adsorption experiments, the concentration of strontium that remained in solution was measured by atomic adsorption spectrophotometer (AAS, TAS-990). In order to investigate the effect of co-existing ions for adsorption process, 
the tested solution contained $0.01,0.1$ and $1 \mathrm{~mol} \mathrm{~L}^{-1} \mathrm{NaCl}, \mathrm{KCl}, \mathrm{MgCl}_{2}, \mathrm{CaCl}_{2}$, respectively. The initial concentration of $\mathrm{Cs}^{+}$and $\mathrm{Sr}^{2+}$ in this solution was adjusted to $50 \mathrm{mg} \mathrm{L}^{-1}$. The artificial seawater composition was from previous article and the concentration of $\mathrm{Cs}^{+}$and $\mathrm{Sr}^{2+}$ was $50 \mathrm{mg} \mathrm{L}^{-1}$ in this solution[12].

The uptake amounts per gram of Prussian blue nanorods were evaluated from the change in solution concentration using Eq (1):

$$
q=\frac{C_{0}-C_{t}}{M} \times V
$$

The distribution coefficient was calculated by Eq (2):

$$
K_{d}=\frac{C_{0}-C_{t}}{C_{t}} \times \frac{V}{M}
$$

where $q\left(\mathrm{mg} \mathrm{g}^{-1}\right)$ is the uptake capacity, $C_{0}\left(\mathrm{mg} \cdot \mathrm{L}^{-1}\right)$ is the initial concentration of strontium solution, $C_{t}\left(\mathrm{mg} \mathrm{L}^{-1}\right)$ is the final concentration in aqueous solution, $\mathrm{M}(\mathrm{g})$ is the mass of adsorbent, $\mathrm{V}(\mathrm{L})$ is the volume of the solution, $K_{d}\left(\mathrm{~mL} \mathrm{~g}^{-1}\right)$ is the distribution coefficient.

\section{Result and discussion}

\section{Characterization of Prussian blue nanorod}

FT-IR spectrum often used qualitatively analyzed the chemical structure of test sample. Fig. 1(a) shows the FT-IR spectrum of Prussian blue nanorod. The adsorption

peak at $3424 \mathrm{~cm}^{-1}$ was due to nonsymmetric stretching vibration of $-\mathrm{OH}$ which ascribed to crystal $\mathrm{H}_{2} \mathrm{O}$ in Prussian blue. The sharp peak at 2070 and $595 \mathrm{~cm}^{-1}$ were ascribed to the vibration of $\mathrm{C} \equiv \mathrm{N}$ and $\mathrm{Fe}-\mathrm{CN}$ bond $[13]$ and that confirmed the final products were Prussian blue. The peak at 2911, 2834 and $1410 \mathrm{~cm}^{-1}$ revealed the symmetric and asymmetric stretching vibration of $\mathrm{CH}_{2}$ and the vibration of $\mathrm{C}-\mathrm{H}$ bend which all from the residual CTAB on PB surface[14]. 

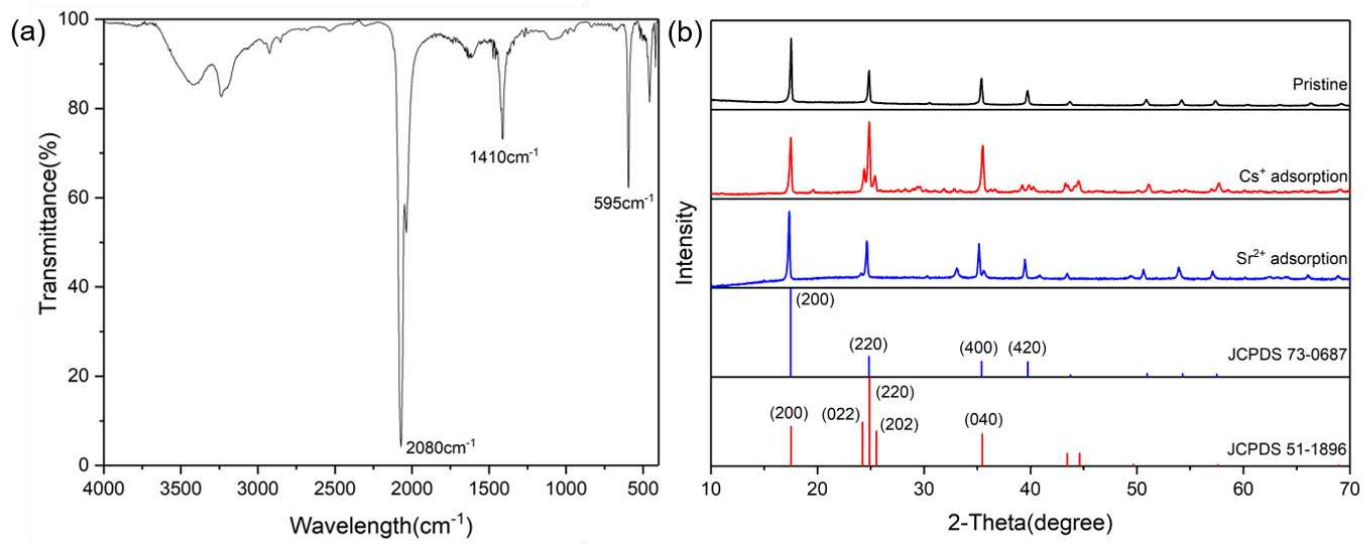

Fig. 1. FT-IR spectrum(a) and XRD pattern(b) of Prussian blue nanorod

The morphology of Prussian blue nanorod was shown in Fig. 2(a) and (b). It was observed that many tetragonal nanorods were stacked together and the aspect ratio of PB nanorods were greater than 10 . The length range of nanorod from 1.5 to $3 \mu \mathrm{m}$ and the diameter of nanorod was nearly $150 \mathrm{~nm}$. Fig. 2(c) is HRTEM image of Prussian blue nanorod, in which PB nanorod had a regular rectangle lengthwise section and a dense crystal surface, the size of PB nanorod in HRTEM image was similar to Fig. 2(a). The crystal structure of Prussian blue nanorod was characterized by XRD and HRTEM. The XRD pattern of PB nanorod was shown in Fig 1(b). All reflection peaks were indexed to the ferric ferrocyanide (JCPDS 73-0687) with the lattice constants of $\mathrm{a}=10.13 \AA$. The extremely narrow and intensity peak at indicated that as-obtained products may had greater crystalline and special morphology. Fig 2(d) was HRTEM image of PB nanorod, the measured lattice fringe with an interplanar spacing of about $0.506 \mathrm{~nm}$ are indexed to the (200) plane of PB nanorod[15], it indicated that Prussian blue nuclei grown as nanorod in the direction of [100], this result also agreed well with XRD pattern. Fig. 2(e) shown the SAED image of PB nanorod, which indicated that PB nanorod was a single crystal and faced-centered cubic structure. The water content of PB nanorod was calculated by TG curves, from room temperature to $250^{\circ} \mathrm{C}[16]$, the $\mathrm{PB}$ nanorod only lost $8.9 \%$ of totally weight, which indicated that PB nanorod possessed few zeolitic water and $\mathrm{Fe}(\mathrm{CN})_{6}$ vacancies. The $\mathrm{N}_{2}$ adsorption-desorption isotherms and pore size distribution of PB nanorods were showed in Fig. 3 (b), the calculated BrunauerEmmett-Teller (BET) surface area was $4.4392 \mathrm{~m}^{2} \mathrm{~g}^{-1}$ and the total pore volume was 
$0.0126 \mathrm{~cm}^{3} \mathrm{~g}^{-1}$.

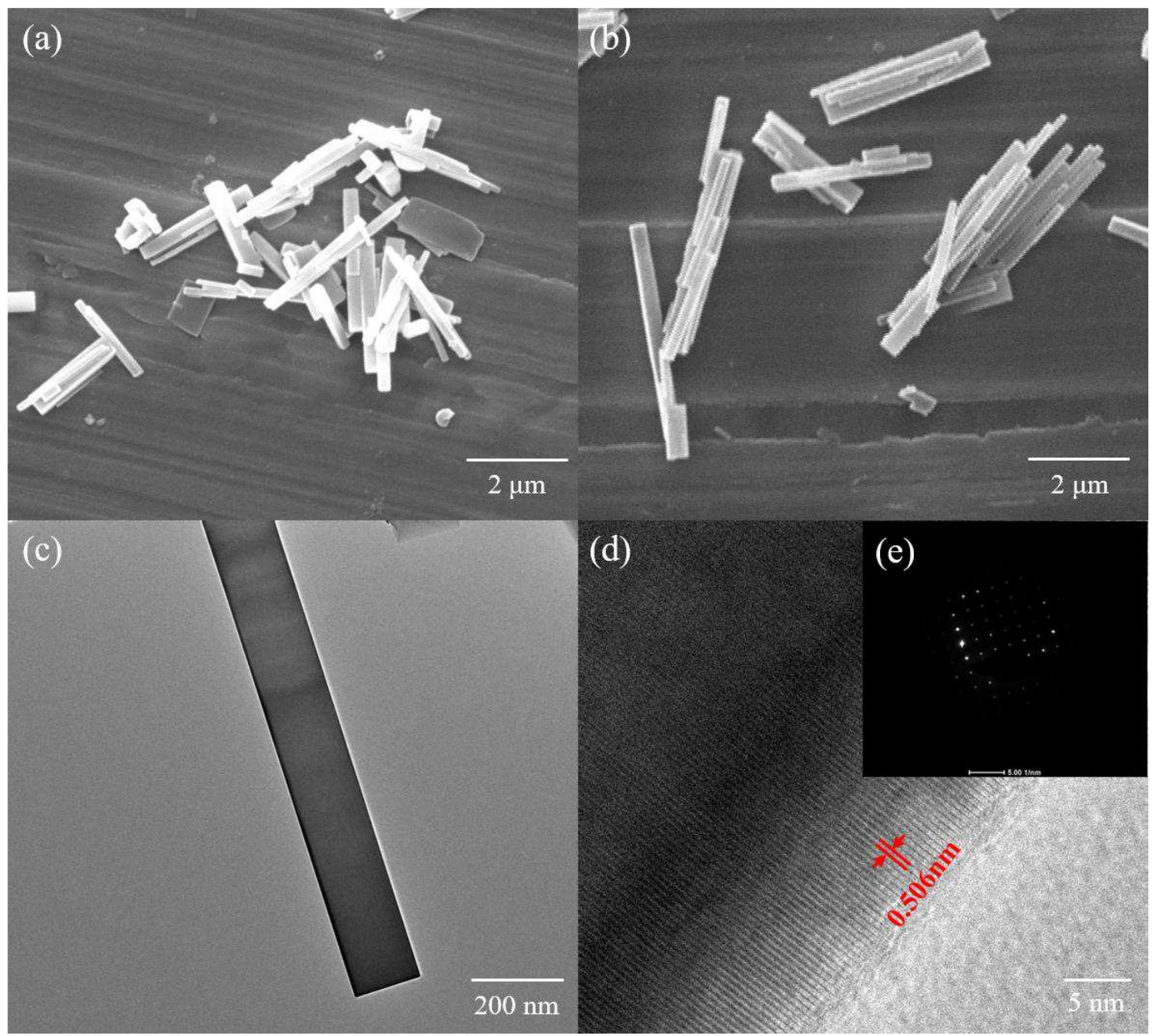

Fig. 2. $\operatorname{SEM}(a, b)$ and $\operatorname{HRTEM}(\mathrm{c}, \mathrm{d})$ images of $P B$ nanorod (inset showed SAED pattern)
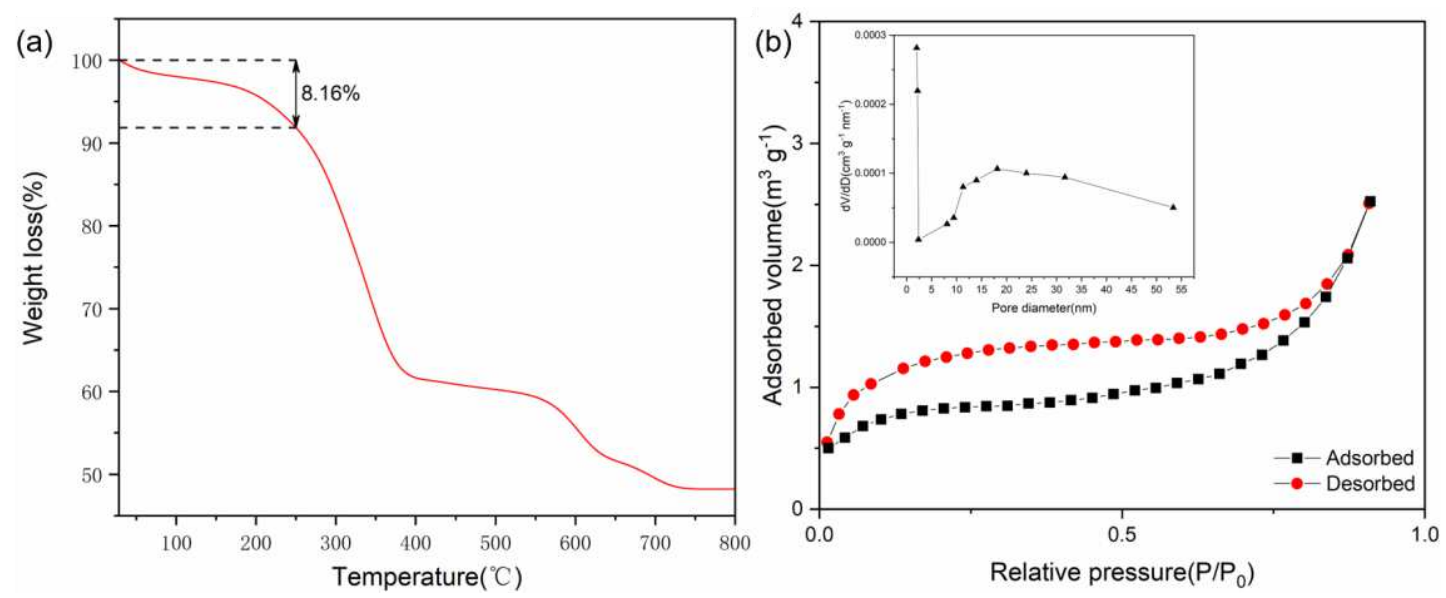

Fig. 3. (a) TG curve, (b) $\mathrm{N}_{2}$ adsorption-desorption isotherms and pore size distribution (inset) of PB nanorods

In order to investigated the morphology of PB nanorods under different growth 
condition, we carried out a series of controlled experiments. CTAB was a commonly cationic surfactant which played a dominant role in the formation of microemulsion. Fig. 4 presented the reaction products of $5 \mathrm{mmol}, 7.5 \mathrm{mmol}, 17.5 \mathrm{mmol}, 20 \mathrm{mmol} \mathrm{CTAB}$, respectively. In Fig. 4 (a) (b), the reaction products at low concentration of CTAB contained a lot of lamellar PB, the products at $7.5 \mathrm{mmol}$ CTAB had larger proportion rod-like Prussian blue and the lamellar PB was more regular than products of 5 mmol. With the increased of concentration of CTAB, the amount of lamellar PB decreased and the proportion of one dimensional structured PB in as-obtained products was increased. In Fig. 4(c), the width of tetragonal PB rod was closed to $1 \mu \mathrm{m}$ and several PB nanorods were agglomerated that formed a sheet of Prussian blue. When the CTAB amount increased to $20 \mathrm{mmol}$, the final products contained many unregular Prussian blue cuboid with width range from $300 \mathrm{~nm}$ to $2 \mu \mathrm{m}$ and length range from $1.5 \mu \mathrm{m}$ to $3 \mu \mathrm{m}$. According to the above SEM images, the content of CTAB in solvent had a great influence to the final products morphology. Some research shown that bromine ions which released by $\mathrm{CTAB}$ were preferential chemisorption on [100] facet of crystal[17,18]. At low concentration of $\mathrm{Br}$, some crystal facet not coated by bromine ions that induced Prussian blue seed grown in both directions, thus formed twodimensional lamellar PB. With the concentration of $\mathrm{Br}$ ions increased, the lamellar products gradually decreased until disappeared, however, the aggregate PB nanorods were increasing and the large size PB bars were appeared frequently. According to the experiment result, it was obviously that final products which reacted in $15 \mathrm{mmol}$ CTAB condition were suitable radioactive nuclide adsorbent. 


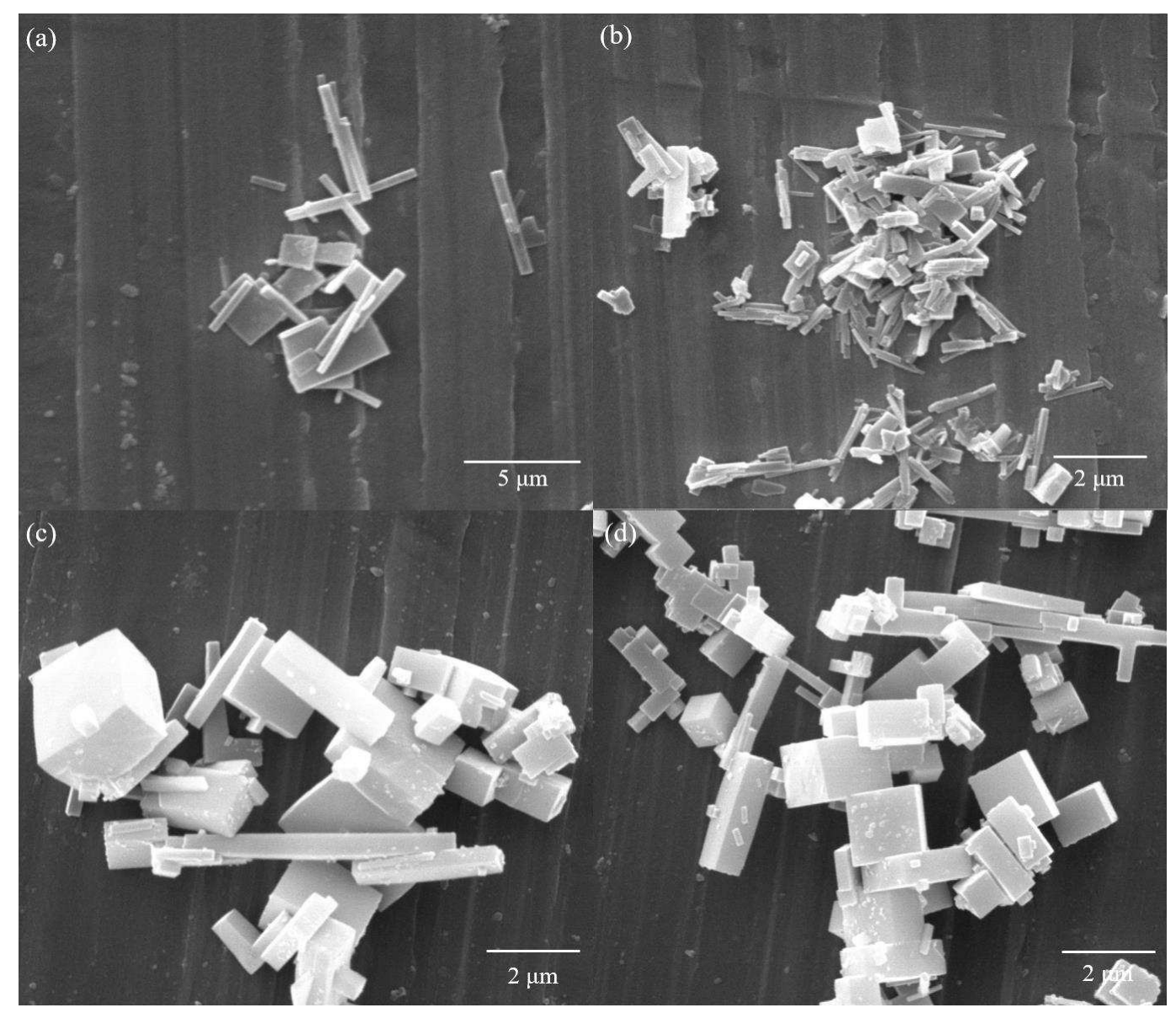

Fig. 4. SEM images of PB obtained from different amount of CTAB (a) $5 \mathrm{mmol}$ (b)

$$
7.5 \mathrm{mmol}(\mathrm{c}) 17.5 \mathrm{mmol} \text { (d) } 20 \mathrm{mmol}
$$

\section{Adsorption kinetics}

Fig 5 displayed the adsorption capacity of Prussian blue nanorod for $\mathrm{Cs}^{+}$and $\mathrm{Sr}^{2+}$ at different time intervals in variety initial concentration. It was observed that the adsorption capacity increased with time extension for all concentrations at initial stage, then adsorption rate was slow down and reached adsorption equilibrium $2 \mathrm{~h}$ later. On changing the initial ions concentration as 100,200 and $500 \mathrm{mg} \mathrm{L}^{-1}$, the equilibrium adsorption amount was 90.65, 157.05 and $206.92 \mathrm{mg} \mathrm{g}^{-1}$ for $\mathrm{Cs}^{+}$and 99.90, 189.92 and $270.75 \mathrm{mg} \mathrm{g}^{-1}$ for $\mathrm{Sr}^{2+}$, that due to the driving force of the concentration gradient overcame mass transfer resistance of ions between the aqueous and solid phase.[19] 

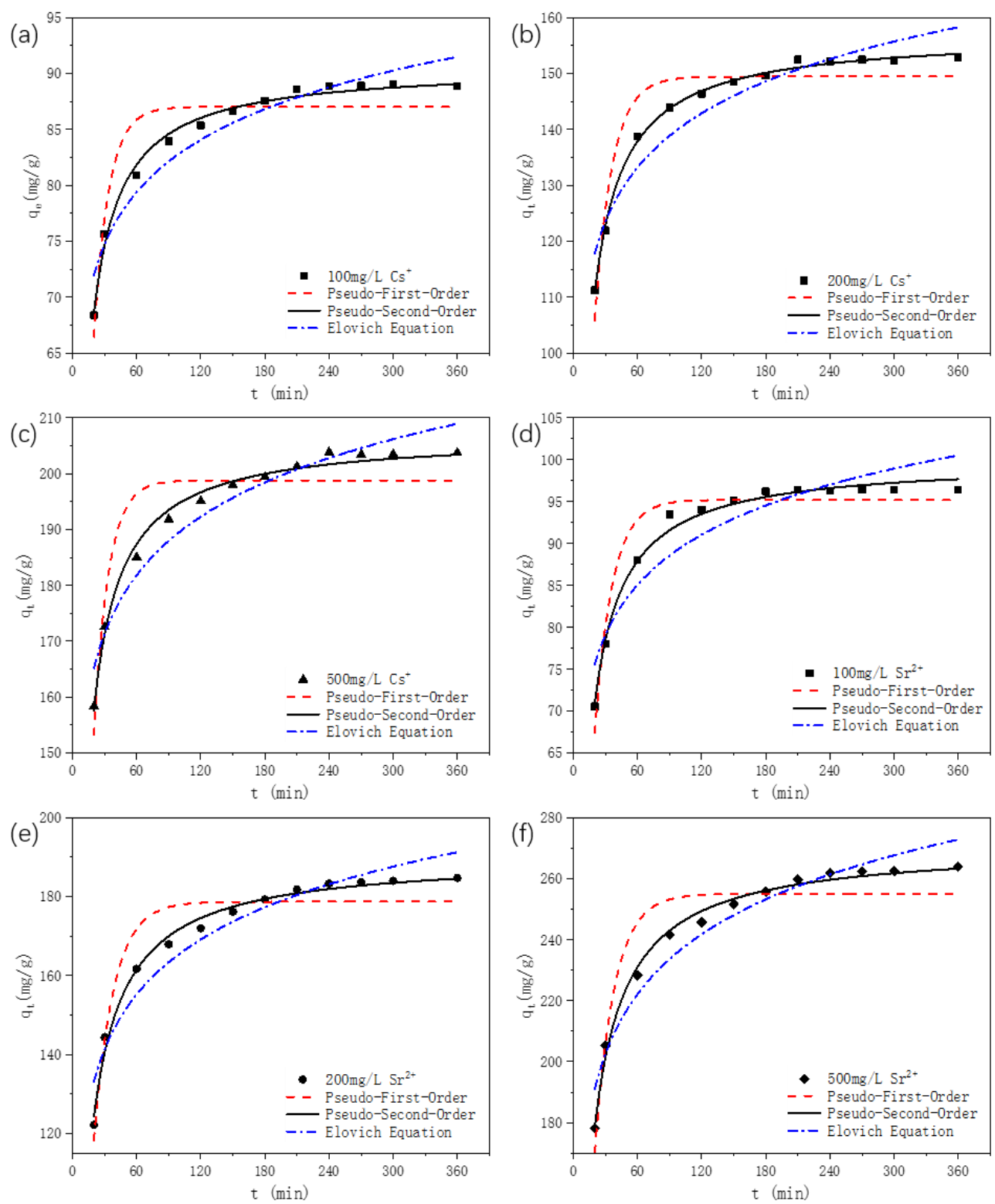

Fig. 5. adsorption kinetic of PB nanorod at (a) 100, (b)200, (c) $500 \mathrm{mg} \mathrm{L}$ (c) $\mathrm{Cs}^{+}$ solution and (d) 100 , (e) 200, (f) $500 \mathrm{mg} \mathrm{L}^{-1} \mathrm{Sr}^{2+}$ solution

In study of adsorbent adsorption process, we often used three adsorption kinetic equation: pseudo first-order equation, pseudo second-order equation and Elovich equation[20,21]. These equations are shown in Eq. (3)-(5).

$$
\begin{gathered}
q_{t}=q_{e}\left(1-e^{-k_{1} t}\right) \\
q_{t}=\frac{q_{e}^{2} k_{2} t}{1+q_{e} k_{2} t} \\
q_{t}=b \ln (a b)+b \ln (t)
\end{gathered}
$$


where $\mathrm{q}_{\mathrm{e}}$ and $\mathrm{q}_{\mathrm{t}}$ are the adsorption amount $\left(\mathrm{mg} \mathrm{g}^{-1}\right)$ at the equilibrium and at time $\mathrm{t}$ (min), respectively. $\mathrm{k}_{1}\left(\mathrm{~min}^{-1}\right)$ and $\mathrm{k}_{2}\left(\mathrm{~g}(\mathrm{mg} \mathrm{g})^{-1}\right)$ are the rate constants of pseudo firstorder and pseudo second-order equation. In Elovich equation, a represent initial adsorb rate $\left(\mathrm{mg}(\mathrm{g} \mathrm{min})^{-1}\right)$ and $\mathrm{b}$ is desorption constant $(\mathrm{g} \mathrm{mg})$. The value of above parameters were listed in Table 1.

As shown in Table 1, the experimental data for each initial concentration displayed a good correspond with the pseudo-second-order kinetic model, the correlation coefficient were higher than pseudo-first-order and Elovich kinetic model. It confirmed that pseudo-second-order equation was the best model to describe the adsorption process of PB nanorod. $\mathrm{k}_{2}$ was a constant related to the adsorbed rate, a large $\mathrm{k}_{2}$ represented adsorption process would take a short time to reach equilibrium[22]. Therefore, the obtained large $\mathrm{k}_{2}$ indicated that PB nanorod spent less time to remove $\mathrm{Cs}^{+}$and $\mathrm{Sr}^{2+}$.

Table 1 The fitting kinetic parameters of PB nanorod

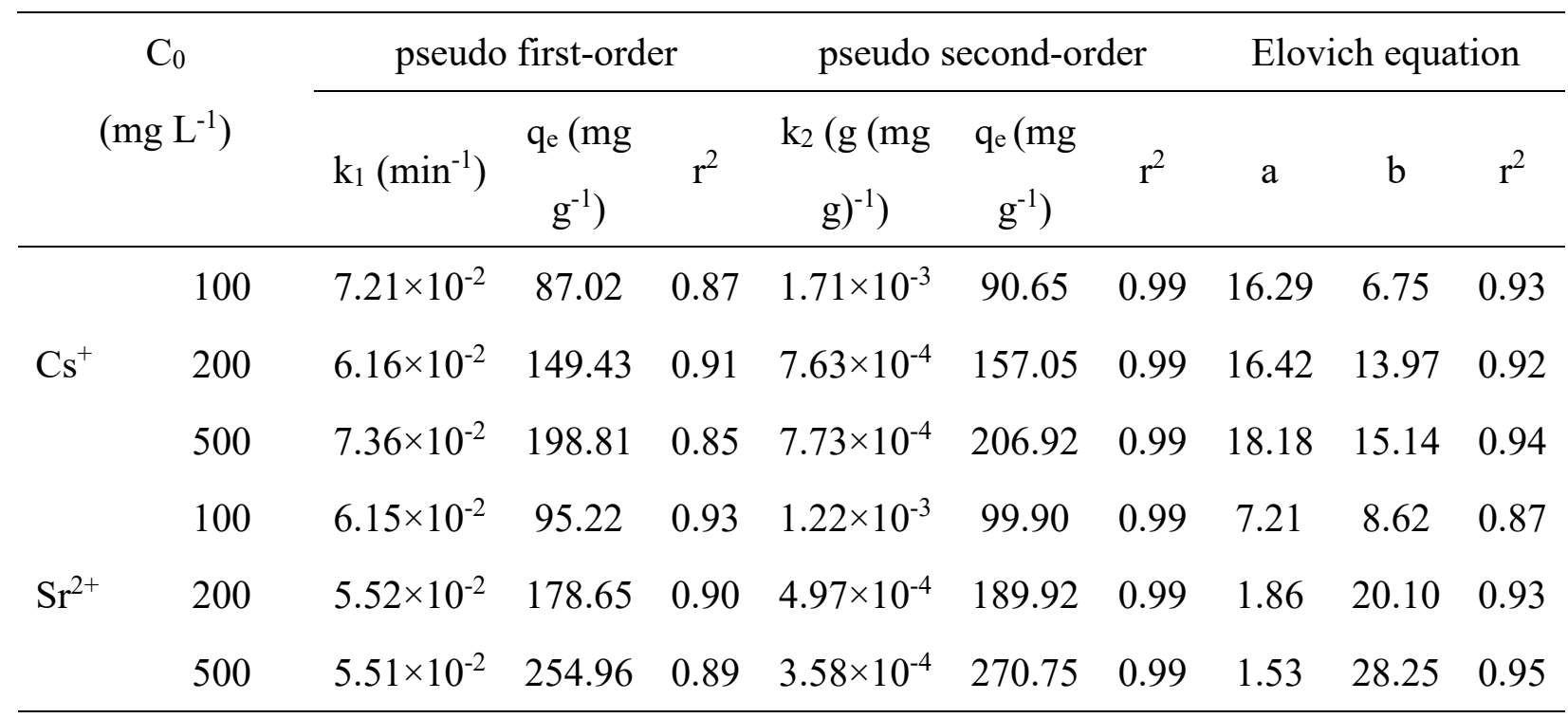

\section{Adsorption isotherms and thermodynamics}

The adsorption isotherm was an important pathway for understanding the characteristic of adsorption system and isotherm would provide physical chemistry data of the adsorption process. In order to fully understand the adsorption characteristic of cesium and strontium onto Prussian blue nanorod, the adsorption experiments data were fitted by three different isotherms. 
Langmuir isotherm assumed that adsorption occurs on homogeneous surface, that is mean the enthalpy change and adsorption activation energy of each molecule are fixed, and the whole adsorption process is monolayer adsorption[14,23], as presented by

$$
q_{e}=\frac{q_{m} k_{L} C_{e}}{1+k_{L} C_{e}}
$$

In addition, the separation factor $\mathrm{R}_{\mathrm{L}}$ which as dimension constant is obtained by Langmuir isotherm constant, the calculate equation was given by

$$
R_{L}=\frac{1}{1+k_{L} c_{i}}
$$

Freundlich isotherm assumed that adsorption occurs on heterogeneous surfaces and that adsorbents and adsorbents interacted with each other. Freundlich isotherm often applied in multilayer adsorption process[24], as presented by

$$
q_{e}=k_{F} c_{e}^{\frac{1}{n}}
$$

Redlich-Peterson isotherm was combination of the Langmuir and Freundlich isotherm, the equation was given by

$$
q_{e}=\frac{k_{R} c_{e}}{1+a c_{e}^{\beta}}
$$

where $q_{e}$ and $q_{m}$ were the adsorption amount $\left(\mathrm{mg} \mathrm{g}^{-1}\right)$ at the equilibrium and maximum adsorption capacity. $c_{e}\left(\mathrm{mg} \mathrm{L}^{-1}\right)$ and $c_{i}$ were the concentration of strontium at the equilibrium and at the initial. $k_{L}\left(\mathrm{~L} \mathrm{mg}^{-1}\right), k_{F}(\mathrm{mg} / \mathrm{g}), k_{R}\left(\mathrm{~L} \mathrm{~g}^{-1}\right)$ and $a\left(\mathrm{~L} \mathrm{mg}^{-1}\right)$ were Langmuir isotherm constant, Freundlich isotherm constant and Redlich-Peterson isotherm constant, respectively. $n$ and $\beta$ were exponent. The value of parameters was summarized in Table 2.

Fig. 6 showed the three isotherm models applied to experimental data, the adsorption amount of PB nanorod were increased with the temperature increasing both $\mathrm{Cs}^{+}$and $\mathrm{Sr}^{2+}$. Langmuir isotherm exhibited the highest correlation coefficients in three isotherms, which suggested that PB nanorod surface was homogenous and adsorption process of $\mathrm{Cs}^{+}$and $\mathrm{Sr}^{2+}$ was monolayer adsorption. The maximum adsorption capacity calculated by Langmuir isotherm were 194.26, 232.58 and $284.74 \mathrm{mg} \mathrm{g}^{-1}$ for $\mathrm{Cs}^{+}$and 256.62, 290.94 and $316.58 \mathrm{mg} \mathrm{g}^{-1}$ for $\mathrm{Sr}^{2+}$ at $298 \mathrm{~K}, 303 \mathrm{~K}$ and $308 \mathrm{~K}$, respectively. The value of $R_{L}$ would classify shape of isotherm was unfavorable $\left(R_{L}>1\right)$, linear $\left(R_{L}=1\right)$, 
irreversible $\left(\mathrm{R}_{\mathrm{L}}=0\right)$ and favorable $\left(0<\mathrm{R}_{\mathrm{L}}<1\right)$. we obtained value of $\mathrm{R}_{\mathrm{L}}$ was $0.29,0.35$, 0.47 in $\mathrm{Cs}^{+}$sorption and $0.27,0.35,0.38$ in $\mathrm{Sr}^{2+}$ sorption, the value confirmed that the adsorption process of $\mathrm{Cs}^{+}$and $\mathrm{Sr}^{2+}$ onto $\mathrm{PB}$ nanorod was favorable. The R-P equation was approximate to Henry's law in low adsorbate concentration and approximate to Freundlich isotherm in high concentration[25]. When exponent $\beta=1$, the equation changed into Langmuir model, when $\beta$ trend to 0 , the R-P equation was more Freundlich. The $\beta$ values were all close to 1 in Table.2, which confirmed a Langmuir type mechanism.
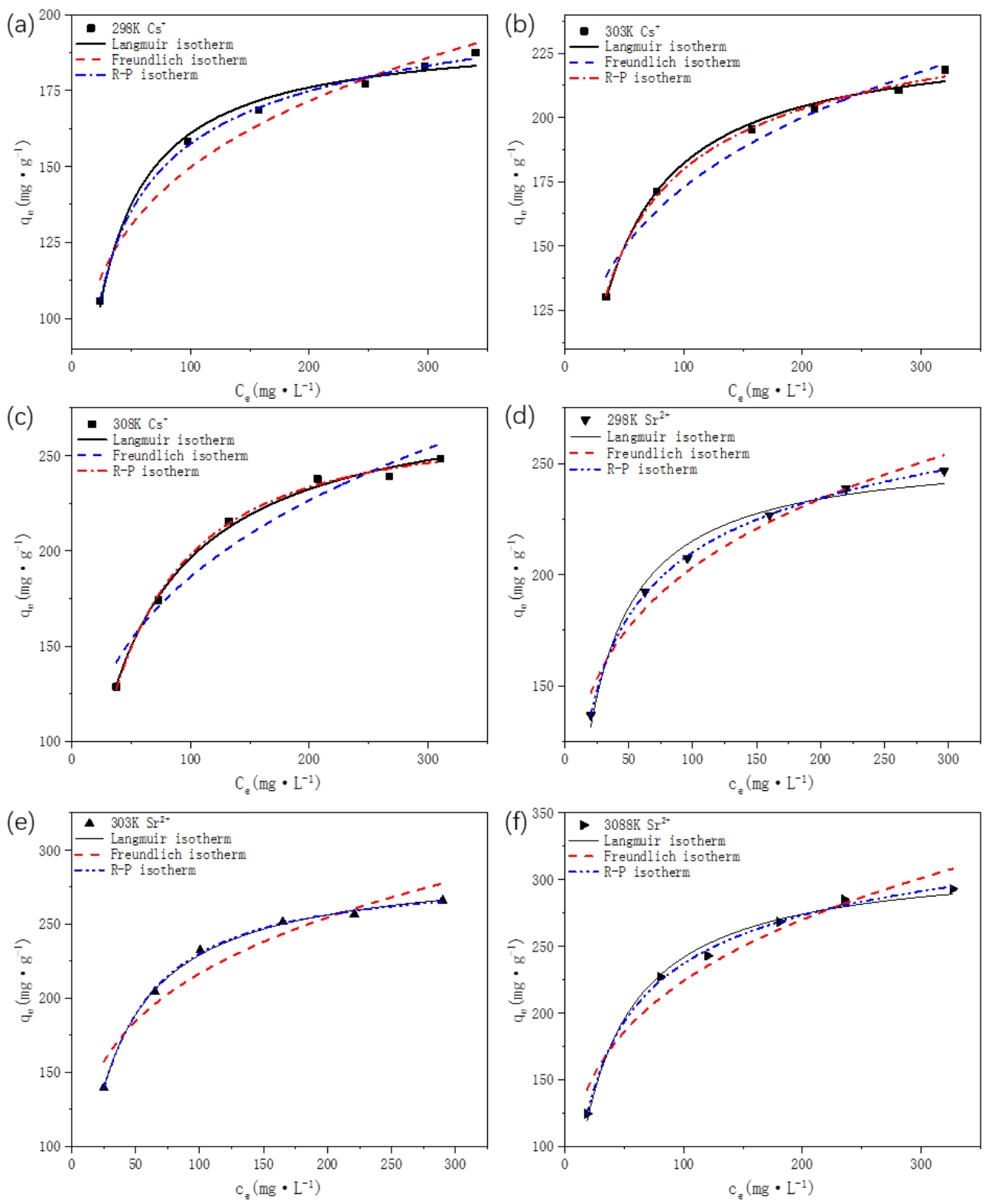
Fig. 6. adsorption isotherms of $\mathrm{PB}$ nanorod for $\mathrm{Cs}^{+}$at $298 \mathrm{~K}(\mathrm{a}), 303 \mathrm{~K}(\mathrm{~b}), 308 \mathrm{~K}(\mathrm{c})$ and

$$
\mathrm{Sr}^{2+} \text { at } 298 \mathrm{~K}(\mathrm{~d}), 303 \mathrm{~K}(\mathrm{e}), 308 \mathrm{~K}(\mathrm{f})
$$

Table 2 The fitting isotherm parameters of PB nanorod

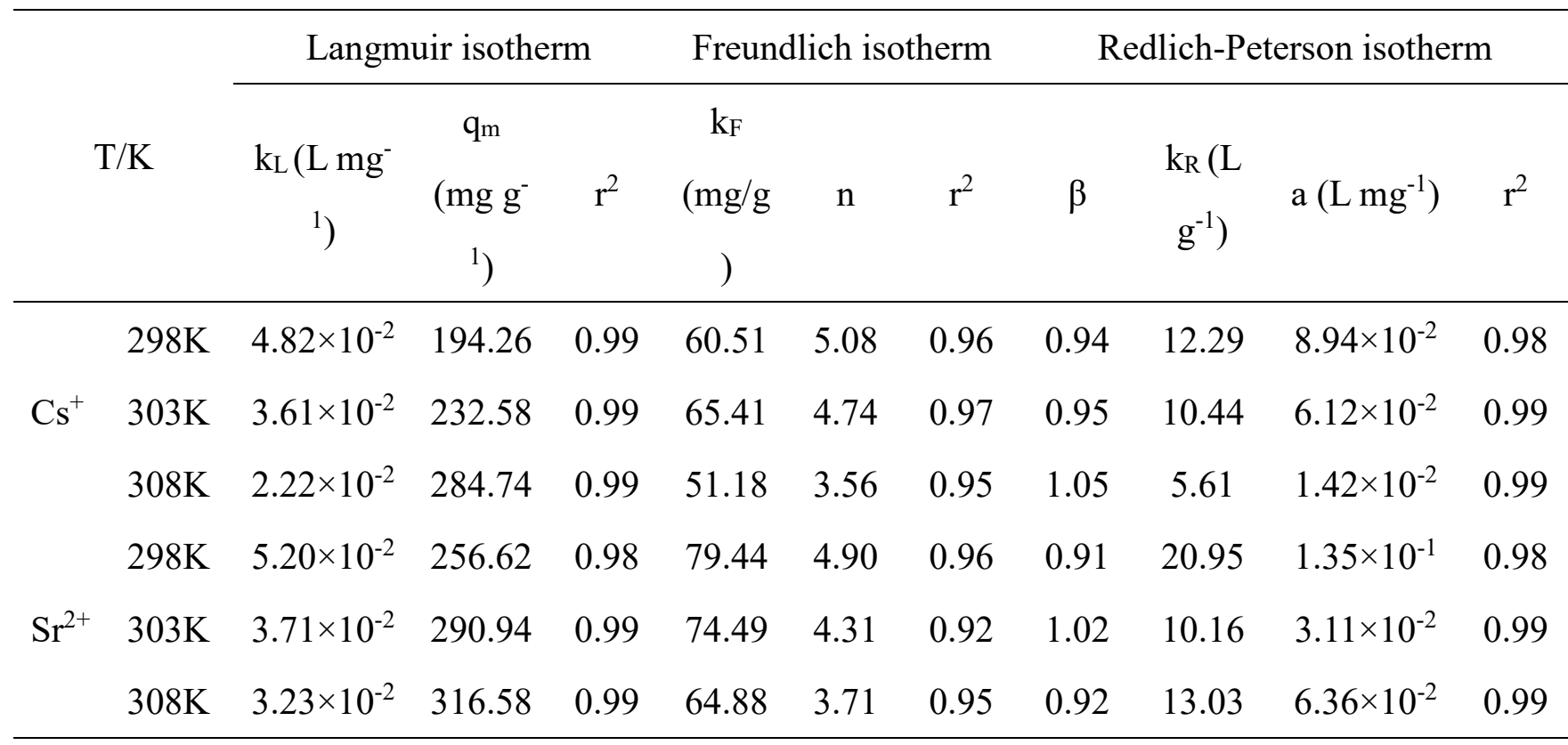

Table 3 showed the reported various adsorbent for $\mathrm{Cs}^{+}$and $\mathrm{Sr}^{2+}$ adsorption along with their maximum adsorption capacity. The as-synthesized Prussian blue nanorod exhibited higher adsorption capacity than most reported adsorbents, especially for removal of $\mathrm{Sr}^{2+}$.

Table 3 Summary of reported adsorbent for $\mathrm{Cs}^{+}$and $\mathrm{Sr}^{2+}$ adsorption

\begin{tabular}{llll}
\hline Adsorbent & $\mathrm{Q}_{\max }-\mathrm{Cs}\left(\mathrm{mg} \mathrm{g}^{-1}\right)$ & $\mathrm{Q}_{\max }-\mathrm{Sr}\left(\mathrm{mg} \mathrm{g}^{-1}\right)$ & Reference \\
\hline $\mathrm{PB} / \mathrm{Fe} 3 \mathrm{O} 4 / \mathrm{GO}$ & 55.6 & & {$[26]$} \\
$\mathrm{PB} / \mathrm{RGOF}$ & 18.67 & & {$[27]$} \\
$\mathrm{Zn}-\mathrm{HCF}$ & 24.5 & & {$[28]$} \\
$\mathrm{Zn}-\mathrm{Co}$ PBA & 255 & & {$[29]$} \\
$\mathrm{PB} / \mathrm{NHBC}$ & 125.31 & 40.5 & {$[30]$} \\
$\mathrm{MnO}_{2}$ & & 30.2 & {$[31]$} \\
$\mathrm{MnO}_{2}-\mathrm{Sb}_{2} \mathrm{O}_{5}$ & & 205.1 & {$[32]$} \\
$\mathrm{PBA} / \mathrm{Chitosan}_{\text {CNTs }}$ & 219.8 & 256.62 & {$[33]$} \\
$\mathrm{PB}$ nanorod & 194.26 & This study \\
\hline
\end{tabular}

Adsorption thermodynamics were conducive to understand the degree and driving 
force of the adsorption process and also could deeply analyzed the influence of various factors on the adsorption process. The thermodynamic parameters $\Delta \mathrm{G}^{\circ}, \Delta \mathrm{H}^{\circ}$ and $\Delta \mathrm{S}^{\circ}$ were calculated by Eq (10), Eq (11) and Eq (12)[34].

$$
\begin{gathered}
\Delta \mathrm{G}^{\circ}=\Delta \mathrm{H}^{\circ}-\mathrm{T} \Delta \mathrm{S}^{\circ} \\
\Delta \mathrm{G}^{\circ}=-\mathrm{RT} \ln \mathrm{K}^{\mathrm{o}} \\
\ln \mathrm{K}=\frac{\Delta \mathrm{S}^{\circ}}{\mathrm{R}}-\frac{\Delta \mathrm{H}^{\circ}}{\mathrm{RT}} \\
\mathrm{K}^{\mathrm{o}}=1000 \mathrm{~K}_{\mathrm{L}} \mathrm{M}_{\mathrm{A}}
\end{gathered}
$$

Where $\Delta \mathrm{G}^{\circ}$ was standard Gibbs free energy, $\mathrm{kJ} \mathrm{mol}^{-1} . \Delta \mathrm{H}^{\circ}$ was standard enthalpy, $\mathrm{kJ} / \mathrm{mol} . \Delta \mathrm{S}^{\circ}$ was standard entropy, $\mathrm{J}(\mathrm{mol} \mathrm{K})^{-1}$. In some reference, the value of $\mathrm{K}^{\mathrm{o}}$ could be approximately by the Langmuir isotherm constant $\mathrm{K}_{\mathrm{L}}$, the value conversion between them referred to $\mathrm{Eq}(13)$ due to different unit used in $\mathrm{K}^{\mathrm{o}}$ calculation, $\mathrm{M}_{\mathrm{A}}$ was adsorbate relative atomic mass[34].

As shown in Table 4, the calculated $\Delta \mathrm{G}^{\circ}$ value were $-21.72,-21.35,-20.26 \mathrm{~kJ} \mathrm{~mol}^{-1}$ in $\mathrm{Cs}^{+}$and $-20.87,-20.37,-20.35 \mathrm{~kJ} \mathrm{~mol}^{-1}$ in $\mathrm{Sr}^{2+}$ at 298,303 and $308 \mathrm{~K}$, respectively. Negative $\Delta \mathrm{G}^{\circ}$ value confirmed adsorption process was spontaneous occurred, the value of $\Delta \mathrm{G}^{\circ}$ were increased with the temperature rase, it indicated that high temperature in favor of adsorption, these results were similar with experiment data[35]. $\Delta \mathrm{H}^{\circ}$ and $\Delta \mathrm{S}^{\circ}$ given an insight into type and mechanism of adsorption process. Negative $\Delta \mathrm{H}^{\circ}$ value suggested the exothermic nature of adsorption. In general, the adsorption process was physical adsorption if $2.1<\Delta \mathrm{H}^{\circ}<20.9 \mathrm{~kJ} \mathrm{~mol}^{-1}$. If $\Delta \mathrm{H}^{\circ}>80 \mathrm{~kJ} \mathrm{~mol}^{-1}$, the adsorption process was chemical adsorption[36]. The obtained value of $\Delta \mathrm{H}^{\circ}$ was $-59.05,-51.12 \mathrm{~kJ}$ $\mathrm{mol}^{-1}$ and all between 20.9 and $80 \mathrm{~kJ} \mathrm{~mol}^{-1}$, it perhaps attributed the adsorption mechanism of $\mathrm{Cs}$ and $\mathrm{Sr}$ for $\mathrm{PB}$ nanorod was close to chemical adsorption, ions were caged in lattice defect of $\mathrm{PB}$ nanorod. In addition, negative $\Delta \mathrm{S}^{\circ}$ value reflected the decreased randomness at solid-solution interface during adsorption process.

Table 4 thermodynamic parameters of PB nanorod

\begin{tabular}{ccccc}
\hline \multirow{2}{*}{$\begin{array}{c}\text { Absorbed } \\
\text { element }\end{array}$} & $\mathrm{T}(\mathrm{K})$ & \multicolumn{3}{c}{ Thermodynamic parameters } \\
\cline { 3 - 5 } & & $\Delta \mathrm{G}\left(\mathrm{kJ} \mathrm{mol}^{-1}\right)$ & $\Delta \mathrm{H}\left(\mathrm{kJ} \mathrm{mol}^{-1}\right)$ & $\Delta \mathrm{S}\left(\mathrm{J} \mathrm{mol}^{-1} \mathrm{~K}^{-1}\right)$ \\
\hline $\mathrm{Cs}^{+}$sorption & 298 & -21.72 & -59.05 & -125.01 \\
\hline
\end{tabular}




\begin{tabular}{lllll}
\hline 303 & -21.35 & & \\
& 308 & -20.26 & & \\
& 298 & -20.87 & & \\
$\mathrm{Sr}^{2+}$ sorption & 303 & -20.37 & -51.12 & -101.49 \\
& 308 & -20.35 & & \\
\hline
\end{tabular}

\section{Effect of pH}

In general, Iron hexacyanoferrate $(\mathrm{Fe}-\mathrm{Fe} \mathrm{PB})$ was rapidly converted into $\mathrm{Fe}(\mathrm{OH})_{3}$ in alkaline solution, it was ascribed to ions exchange react between $\mathrm{Fe}(\mathrm{III})$ and $\mathrm{OH}^{-}$, as shown in following equation[37]

$$
\mathrm{Fe}_{4}\left[\mathrm{Fe}(\mathrm{CN})_{6}\right]_{3(\mathrm{~s})}+12 \mathrm{OH}_{(\mathrm{aq})}^{-} \rightarrow 3 \mathrm{Fe}(\mathrm{CN})_{6}^{4-}{ }_{(\mathrm{aq})}+4 \mathrm{Fe}(\mathrm{OH})_{3(\mathrm{~s})}
$$

However, we obtained Fe-Fe PB nanorod possessed a part of resistance to alkaline solution. In Fig. 7(a) and (c), the color of solution which contained Fe-Fe PB changed from blue to yellow immediately when solution $\mathrm{pH} 12$ and 11, it was meant that $\mathrm{Fe}-\mathrm{Fe}$ PB obtained by co-precipitation was immediately transformed to $\mathrm{Fe}(\mathrm{OH})_{3}$. In contrast, $\mathrm{PB}$ nanorod was stable and solution color was not changed at initial when $\mathrm{pH}=12$, after 10 minutes, the color started to turn yellow and all of $\mathrm{PB}$ nanorod transformed $\mathrm{FeOH}_{3}$ until 120min.when $\mathrm{pH}$ value reduced to 11 , the solution color remained blue throughout the whole process that showed the excellent stability of PB nanorod in alkaline solution. In general, the chemical etching process prone to occur on the loose region of crystal which possessed more defects[38-41], and as shown in TEM image and XRD pattern, the high crystallization and low defect of PB nanorod slow down the erosion from hydroxyl ions. 


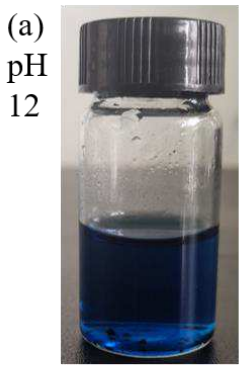

initial

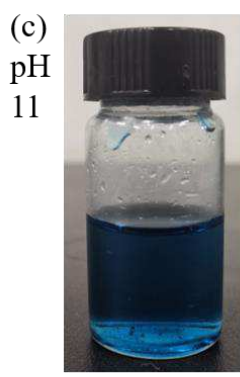

initial

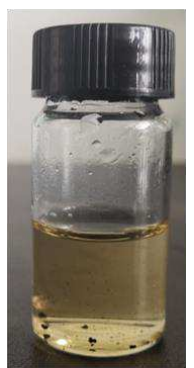

immediate

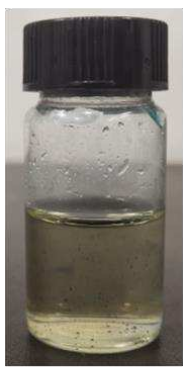

$1 \mathrm{~min}$ (b)

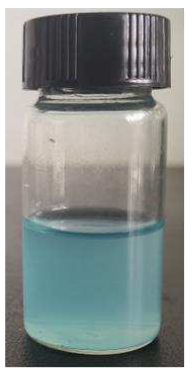

$0 \mathrm{~min}$

(d)

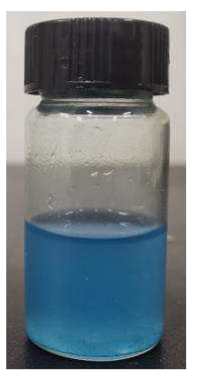

$0 \mathrm{~min}$

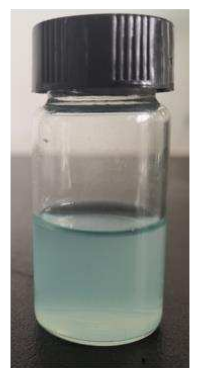

$10 \mathrm{~min}$

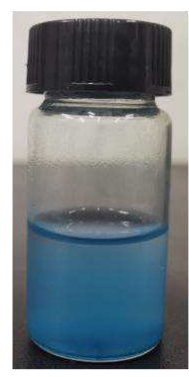

$10 \mathrm{~min}$

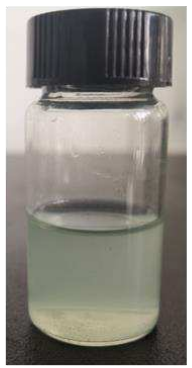

$30 \mathrm{~min}$

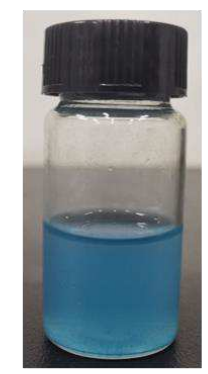

$30 \mathrm{~min}$

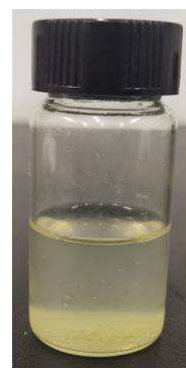

$120 \mathrm{~min}$

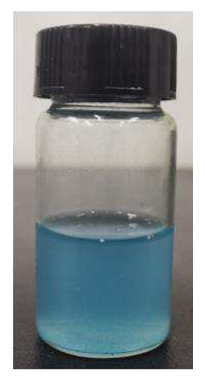

$120 \mathrm{~min}$

Fig. 7. Time dependent photographs of $\mathrm{PB}$ and $\mathrm{PB}$ nanorod in alkaline solution

To investigate adsorption performance of $\mathrm{PB}$ nanorod at variety $\mathrm{pH}$ value, the experiments were conducted at different $\mathrm{pH}$ values from 1 to 10 , since $\mathrm{Sr}^{2+}$ was precipitated when $\mathrm{pH}$ above 10[42]. The res ult was shown in Fig. 8, adsorption capacity of PB increased with $\mathrm{pH}$ value increasing from 1 to 5 both $\mathrm{Cs}^{+}$and $\mathrm{Sr}^{2+}$, then adsorption amount of $\mathrm{Sr}^{2+}$ reached maximum at $\mathrm{pH}$ of 7 and $\mathrm{Cs}^{+}$at $\mathrm{pH}$ of 8 , after that the adsorption capacity decreased with $\mathrm{pH}$ value increased.

The solution $\mathrm{pH}$ affected the degree of ionization and surface charge of adsorbent, all of which could affected adsorption capacity. In acidic $\mathrm{pH}$, the surface charge of adsorbent changed positive, it hindered cation entered inner crystal caused the adsorption amount decrease. In alkaline solution, adsorbent surface changed negative but the Prussian blue framework was unstable lead to the decrease of adsorption capacity, 


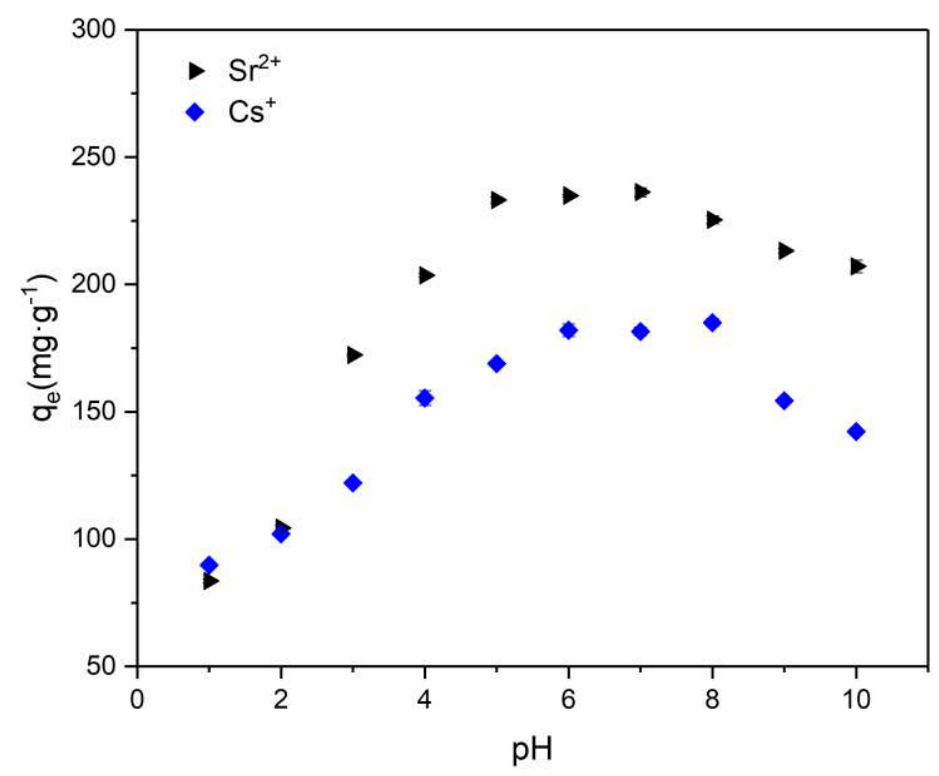

Fig. 8. effect of initial $\mathrm{pH}$ on $\mathrm{Cs}^{+}$and $\mathrm{Sr}^{2+}$ adsorption capacity by $\mathrm{PB}$ nanorod

\section{Effect of co-existing ions}

In general, radioactive waste water contained large amount of co-existing ions like $\mathrm{Na}^{+}, \mathrm{K}^{+}, \mathrm{Mg}^{2+}, \mathrm{Ca}^{2+}$, we investigated the effect of those ions on adsorption performance. As shown in Fig. 9, the different cations had different effect of adsorption on $\mathrm{Cs}^{+}$and $\mathrm{Sr}^{2+} \cdot \mathrm{K}^{+}$played an important role in the process of $\mathrm{Cs}^{+}$being absorbed, the higher concentration of $\mathrm{K}^{+}$, the lower $\mathrm{K}_{\mathrm{d}}$ value of PB. Whereas $\mathrm{Na}^{+}$had little effect of adsorption amount owing to stokes radii of $\mathrm{Na}^{+}$was smaller than $\mathrm{K}^{+}$. While the $\mathrm{Sr}^{2+}$ was adsorbed, alkaline-earth metal ions had stronger resistance to adsorption than alkali metal ions, the $\mathrm{K}_{\mathrm{d}}$ value were less than $1 \mathrm{~L} \mathrm{~g}^{-1}$ both $\mathrm{Mg}^{2+}$ and $\mathrm{Ca}^{2+}$. Otherwise, electrostatic attraction could affect the ions adsorption process. The order of charged density was $\mathrm{Ca}^{2+}>\mathrm{Mg}^{2+}>\mathrm{K}^{+}>\mathrm{Na}^{+[32]}$, that accordance with the result of $\mathrm{Sr}^{2+}$ adsorption experiment.

The distribution coefficient $\mathrm{K}_{\mathrm{d}}$ was often used to present the chemical binding affinity between ions and adsorbent. Ordinarily, $\mathrm{K}_{\mathrm{d}}$ value above $5000 \mathrm{~mL} \mathrm{~g}^{-1}$ was considered good, and more than $50000 \mathrm{~mL} \mathrm{~g}^{-1}$ was considered excellent[43]. In this study, the obtained $K_{d}$ value in different ions were all greater than $5000 \mathrm{~mL} \mathrm{~g}^{-1}$ in low and medium co-existing ions concentration that showed a strong affinity between $\mathrm{Cs}^{+}$, 
$\mathrm{Sr}^{2+}$ and $\mathrm{PB}$ nanorod. Furthermore, the $\mathrm{K}_{\mathrm{d}}$ value of $\mathrm{PB}$ nanorod for $\mathrm{Cs}^{+}$and $\mathrm{Sr}^{2+}$ sorption was 6.52 and $7.49 \mathrm{~L} \mathrm{~g}^{-1}$ in artificial seawater when $\mathrm{C}_{0}=50 \mathrm{ppm}, \mathrm{V} / \mathrm{M}=1 \mathrm{~L} \mathrm{~g}^{-1}$ and $\mathrm{pH}$ of 7 , the result suggested that a high concentration of co-exsiting ions little impact for the binding of $\mathrm{Cs}^{+}$and $\mathrm{Sr}^{2+}$ on $\mathrm{PB}$ nanorod.
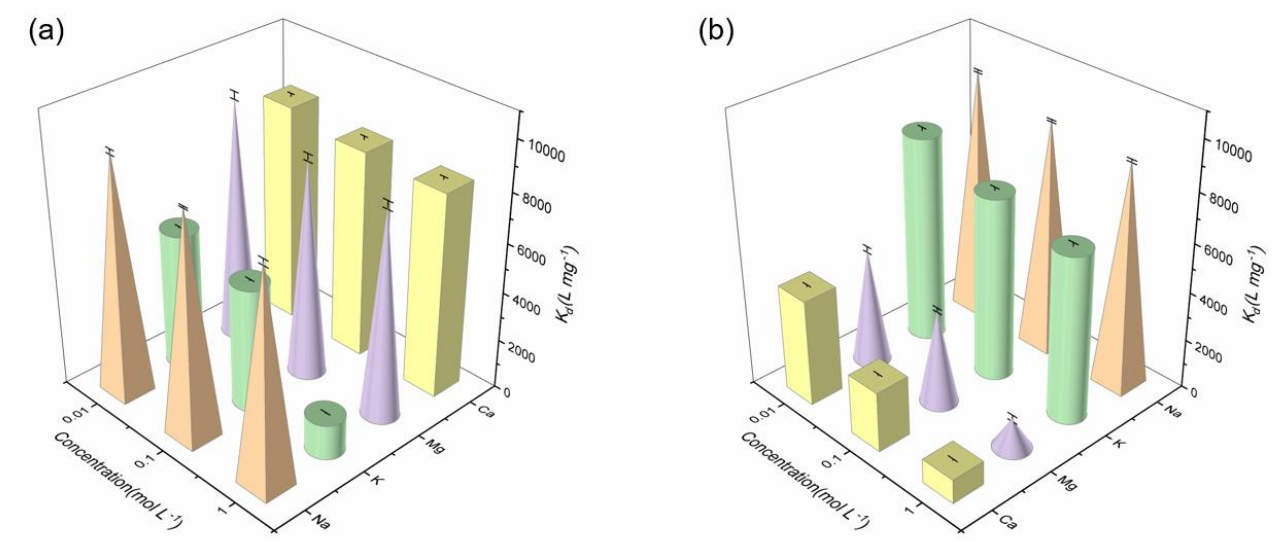

Fig. 9. the effect of co-existing $\mathrm{Na}^{+}, \mathrm{K}^{+}, \mathrm{Mg}^{2+}, \mathrm{Ca}^{2+}$ on the removal efficiency of $\mathrm{PB}$ nanorod for $\mathrm{Cs}^{+}$(a) and $\mathrm{Sr}^{2+}$ (b)

\section{Mechanism of adsorption}

In the past decade, many researchers studied the adsorption mechanism of PB for $\mathrm{Cs}^{+}$, some of them assumed $\mathrm{Cs}^{+}$exchanged with $\mathrm{K}^{+}$in $\mathrm{PB}$ inner crystal structure, others suggested that $\mathrm{Cs}^{+}$was trapped in PB crystal lattice[44,30]. Moreover, the research about Prussian blue adsorbed $\mathrm{Sr}^{2+}$ was rarely mentioned. In this work, we analyzed PB nanorod before and after the $\mathrm{Cs}^{+}$and $\mathrm{Sr}^{2+}$ adsorption by XPS, Mössbauer spectrum and XRD to further investigate adsorption mechanism.

The detailed surface chemistry changed of PB nanorods after adsorption was revealed by XPS analysis. Fig. 10(a) showed XPS spectrum of Prussian blue nanorod and after Cs and Sr adsorption. Fig. 10(b) was high resolution N1S spectra, all spectra of three samples showed two peaks at 397.8 and $402.4 \mathrm{eV}$ which was assigned to $\mathrm{C} \equiv \mathrm{N}-$ Fe ligand and pyrrolic-N respectively[45]. Interestingly, the $\mathrm{C} \equiv \mathrm{N}-\mathrm{Fe}$ ligand peak shifted to $403 \mathrm{eV}$ after $\mathrm{Cs}^{+}$adsorption that could attribute to $\mathrm{Cs}^{+}$was bonded with cyano group. All Fe2p spectra of pristine, after $\mathrm{Cs}^{+}$and $\mathrm{Sr}^{2+}$ adsorption $\mathrm{PB}$ nanorod gave four peaks which presented to two valence of Fe element[46]. The peaks located at 708.96 and $721.70 \mathrm{eV}$ could be indexed to $\mathrm{Fe}^{\mathrm{II}}$ in $\mathrm{Fe} 2 \mathrm{P}_{3 / 2}$ and $\mathrm{Fe} 2 \mathrm{P}_{1 / 2}$, other two peaks at about 
710.48 and $723.82 \mathrm{eV}$ were assigned to $\mathrm{Fe}$ area of XPS spectrum expressed relative quantity of different valence, Table summarized the peak aera of each sample, we could see that pristine PB nanorod total peak aera of $\mathrm{Fe}^{\mathrm{III}}$ only account for 0.32 of that $\mathrm{Fe}^{\mathrm{II}}$. By contrast, the content ratio of $\mathrm{Fe}^{\mathrm{III}}$ to $\mathrm{Fe}^{\mathrm{II}}$ on the surface of $\mathrm{PB}$ nanorod after $\mathrm{Cs}^{+}$and $\mathrm{Sr}^{2+}$ adsorption improved to 0.39 and 0.37. This result indicated that Prussian blue released some $\mathrm{Fe}^{2+}$ in adsorption process. As shown in Cs3d spectra of PB nanorod after $\mathrm{Cs}^{+}$adsorption, two peaks at 725 and $730 \mathrm{eV}$ were allocated to $\mathrm{Cs} 3 \mathrm{~d}_{3 / 2}$ and $\mathrm{Cs} 3 \mathrm{~d}_{5 / 2}$. Fig. 10(f) displayed high-resolution Sr3d spectra, two peaks at $133.93 \mathrm{eV}$ and $135.64 \mathrm{eV}$ characteristic for $3 \mathrm{~d}_{3 / 2}$ and $3 \mathrm{~d}_{1 / 2}$ of strontium. 

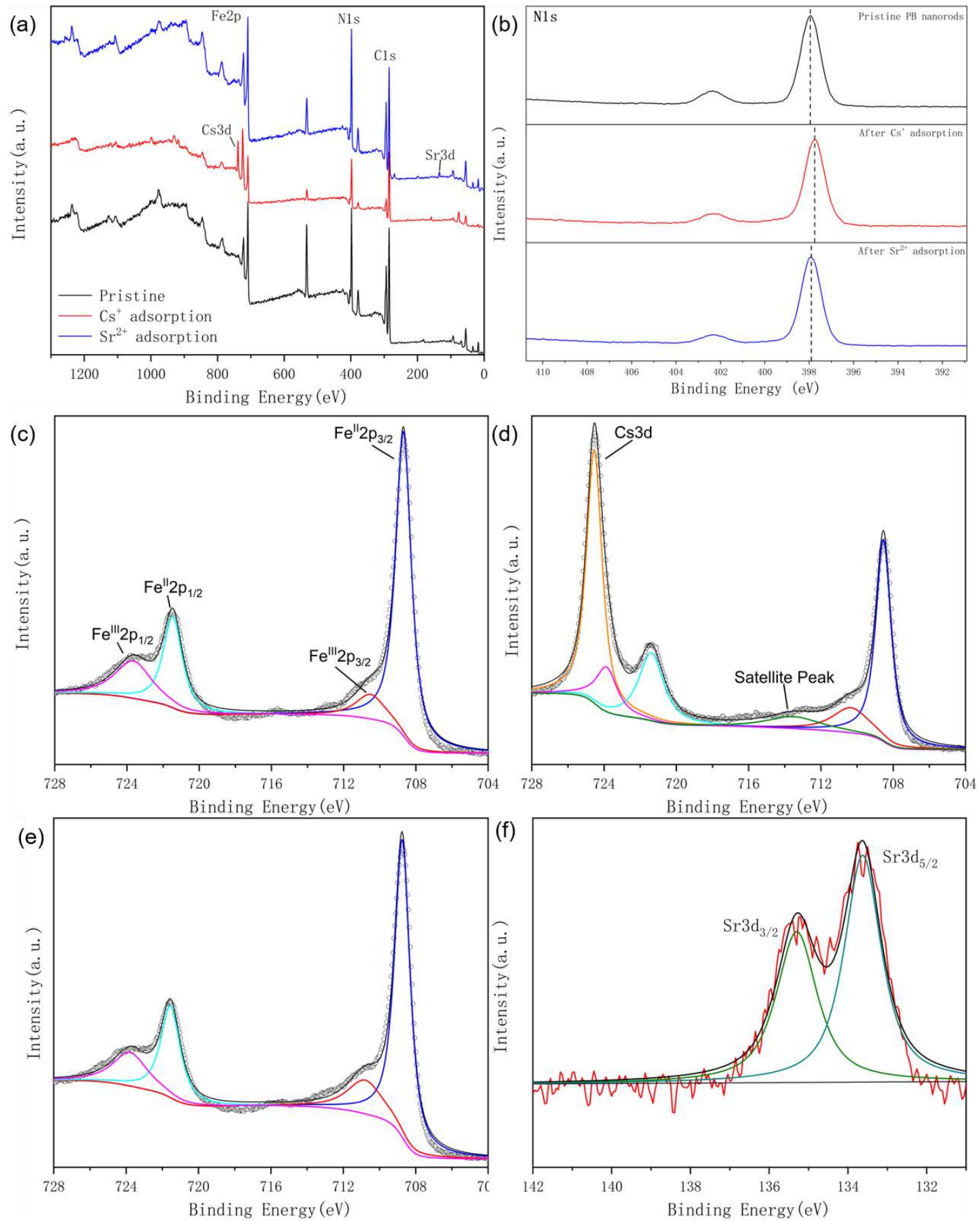

Fig. 10. XPS survey spectra of PB nanorod(a), N 1s spectra (b), Fe 2p spectra of PB nanorods(c), after $\mathrm{Cs}^{+}$adsorption(d) and after $\mathrm{Sr}^{2+}$ adsorption(e), $\mathrm{Sr} 3 \mathrm{~d}$ spectra(f)

Table 5 XPS fitting results of Fe element

\begin{tabular}{cccccc}
\hline \multirow{2}{*}{ samples } & \multicolumn{4}{c}{ Peak aera } & \multirow{2}{*}{$\mathrm{Fe}^{\mathrm{III}} / \mathrm{Fe}^{\mathrm{II}}$} \\
\cline { 2 - 4 } & $\mathrm{Fe}^{\mathrm{II}} 2 \mathrm{p}_{3 / 2}$ & $\mathrm{Fe}^{\mathrm{II}} 2 \mathrm{p}_{1 / 2}$ & $\mathrm{Fe}^{\mathrm{III}} 2 \mathrm{p}_{3 / 2}$ & $\mathrm{Fe}^{\mathrm{III}} 2 \mathrm{p}_{1 / 2}$ & \\
\hline PB nanorod & 602.3 & 220.6 & 90.4 & 172.9 & 0.32 \\
$\mathrm{Cs}^{+}$ & 267.6 & 147.5 & 79.8 & 83.7 & 0.39 \\
\hline
\end{tabular}


adsorption

$\mathrm{Sr}^{2+}$

adsorption

696.9

271.3

181.8

175.0

0.37

XPS only detected the surface elements instead of penetrated deep into sample and Mössbauer spectrum gave an over-arching perspective of the iron valence inside the whole sample[47]. In Mössbauer spectrum analysis, the pristine PB contained 41.95\% $\mathrm{Fe}(\mathrm{II})$ and $58.05 \% \mathrm{Fe}(\mathrm{III})$, there were $46.53 \% \mathrm{Fe}(\mathrm{II})$ and $53.46 \% \mathrm{Fe}(\mathrm{III})$ in $\mathrm{PB}$ nanorod, after $\mathrm{Sr}^{2+}$ adsorption, there were $39.87 \% \mathrm{Fe}(\mathrm{II})$ and $60.13 \% \mathrm{Fe}(\mathrm{III})$. The $\mathrm{Fe}^{2+}$ content of PB only decreased $2.08 \%$ after $\mathrm{Sr}^{2+}$ adsorption that was lower than XPS result, the XRD pattern of $\mathrm{PB}$ also not changed, it was demonstrated that $\mathrm{Sr}^{2+}$ was mainly caged in $\mathrm{PB}$ framework and surface ions exchange was a small proportion. After $\mathrm{Cs}^{+}$adsorption, there were $46.53 \% \mathrm{Fe}(\mathrm{II})$ and $53.46 \% \mathrm{Fe}(\mathrm{III})$ in $\mathrm{PB}$ nanorod, the change of Fe content was larger than $\mathrm{Sr}^{2+}$ adsorption before and after. Interestingly, the XRD pattern of $\mathrm{PB}$ after $\mathrm{Cs}^{+}$adsorption was different from the other two, this indexed to $\mathrm{KMn}\left[\mathrm{Fe}(\mathrm{CN})_{6}\right](\mathrm{JCPDS} 51-1896)$ rather than $\mathrm{Fe}_{3}\left[\mathrm{Fe}(\mathrm{CN})_{6}\right]_{4}(\mathrm{JCPDS} 73-0687)$, the similar result was also obtained by the stoichiometry change of $\mathrm{Fe}^{2+}$ and $\mathrm{Fe}^{3+}$ for $\mathrm{PB}$ nanorod before and after adsorption $\mathrm{Cs}^{+}$.

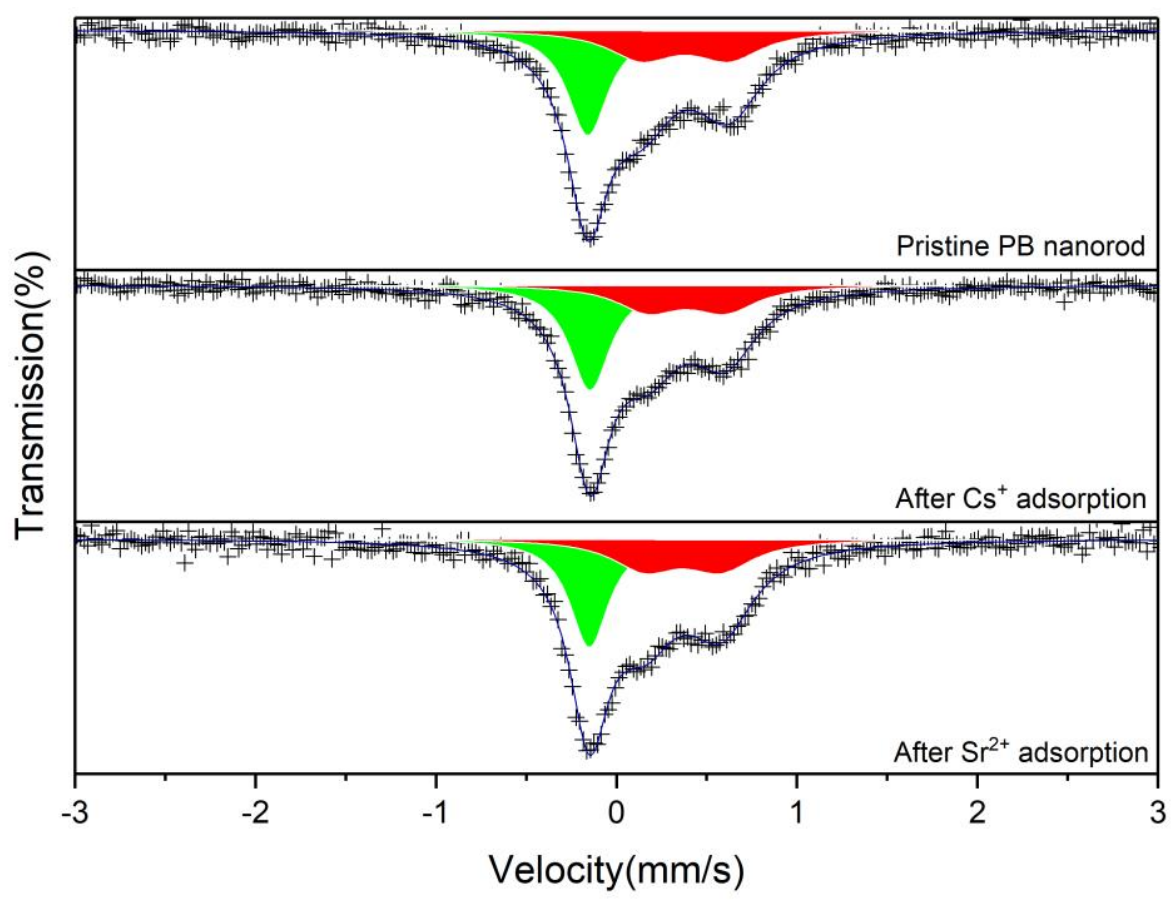


Fig. 11. Mössbauer spectrum of $\mathrm{PB}$ nanorod before and after $\mathrm{Cs}^{+}$and $\mathrm{Sr}^{2+}$ adsorption Table 6 Mössbauer spectrum fitting results

\begin{tabular}{clccc}
\hline Sample & Valence & $\mathrm{IS}\left(\mathrm{mm} \mathrm{s}^{-1}\right)$ & $\mathrm{QS}\left(\mathrm{mm} \mathrm{s}^{-1}\right)$ & ARE $(\%)$ \\
\hline \multirow{2}{*}{ Pristine } & $\mathrm{Fe}^{2+}$ & -0.15822 & & 41.95 \\
& $\mathrm{Fe}^{3+}$ & 0.38089 & 0.48227 & 58.05 \\
$\mathrm{Cs}^{+}$sorption & $\mathrm{Fe}^{2+}$ & -0.14608 & & 46.53 \\
& $\mathrm{Fe}^{3+}$ & 0.38956 & 0.42485 & 53.46 \\
$\mathrm{Sr}^{2+}$ sorption & $\mathrm{Fe}^{2+}$ & -0.15019 & & 39.87 \\
& $\mathrm{Fe}^{3+}$ & 0.36832 & 0.42149 & 60.13 \\
\hline
\end{tabular}

Based on the above result, scheme 1 illustrated the different adsorption mechanism of two cations. Firstly, $\mathrm{Cs}^{+}$could entered the crystal inner caused the PB structure transferred from insoluble to soluble because of that structure possessed a greater capacity for monovalent ion. Secondly, $\mathrm{Sr}^{2+}$ also entered the $\mathrm{PB}$ crystal to achieve decontamination, but that didn't lead structure change. In addition, corresponding to the surface element change from XPS, we could infer that part of $\mathrm{Sr}^{2+}$ exchanged with $\mathrm{Fe}^{2+}$ on the $\mathrm{PB}$ surface. According to the adsorption mechanism, the theoretical adsorption capacity of $\mathrm{PB}$ for $\mathrm{Cs}^{+}$was larger than $\mathrm{Sr}^{2+}$ that contrary to the experimental result, it could ascribe to the electrostatic interaction between $\mathrm{Sr}^{2+}$ and surface residual $-\mathrm{COOH}$ which derived from glucose being reduced. 


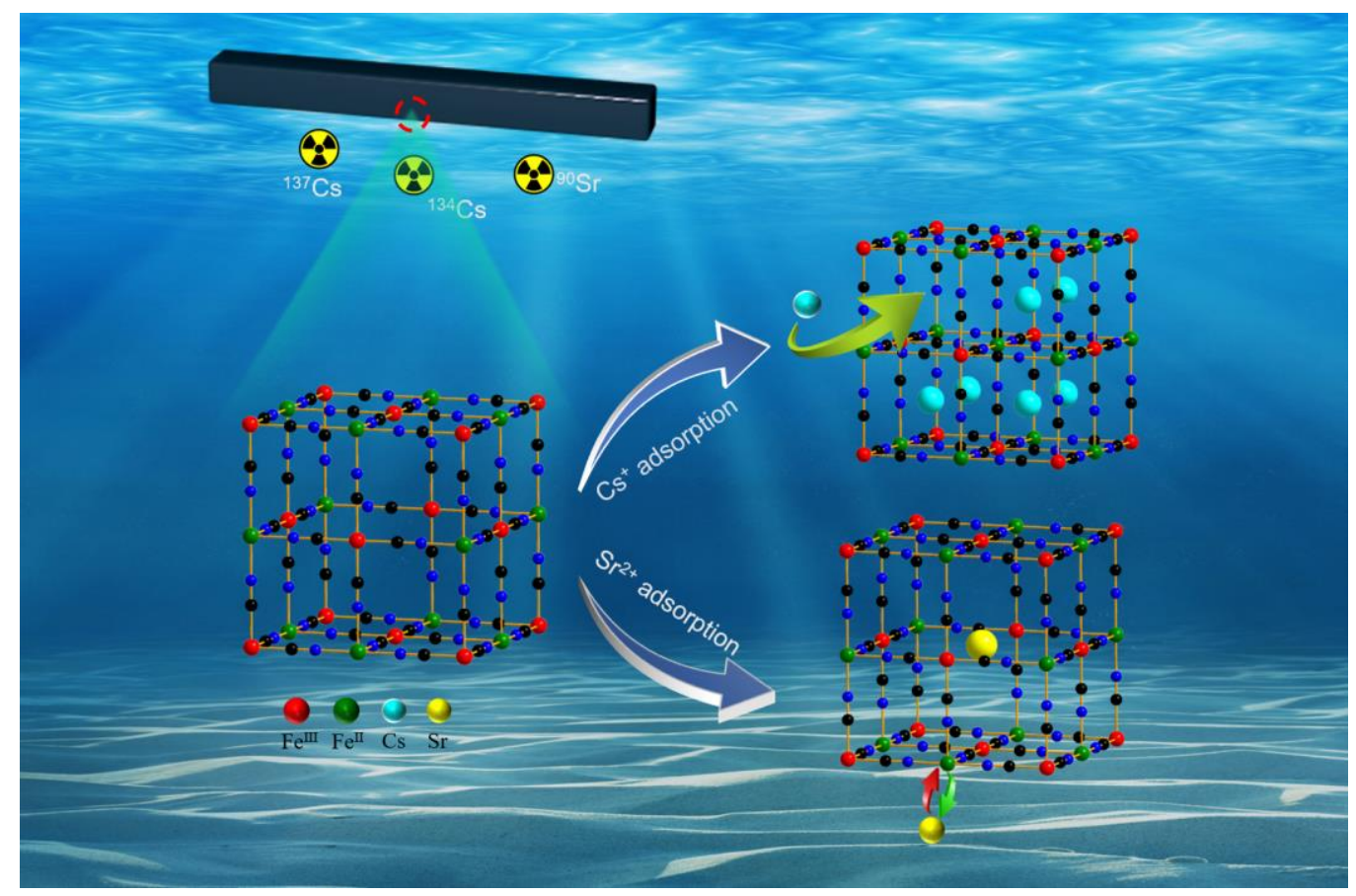

Scheme. 1. illustration of adsorption mechanism

\section{Conclusion}

In this work, PB nanorods were synthesized by hydrothermal microemulsion and applied to adsorption cesium and strontium in simulate radioactive wastewater. Prussian blue nanorod showed a better removal efficiency of $\mathrm{Cs}^{+}$and $\mathrm{Sr}^{2+}$ than ordinary Prussian blue, the adsorption data described well with Langmuir isotherm and pseudosecond-order equation, the maximum adsorption capacity of $\mathrm{PB}$ nanorod was estimated to be $194.26 \mathrm{mg} \mathrm{g}^{-1}$ and $256.62 \mathrm{mg} \mathrm{g}^{-1}$ for $\mathrm{Cs}^{+}$and $\mathrm{Sr}^{2+}$. Moreover, the thermodynamic analysis indicated that the adsorption process was spontaneous and endothermic in nature. The analysis result by XPS, XRD and ${ }^{57} \mathrm{Fe}$ Mössbaure spectrum revealed that $\mathrm{Cs}^{+}$entered in $\mathrm{PB}$ crystal to generate a new phase, the most of $\mathrm{Sr}^{2+}$ was trapped in internal crystal and the other exchanged $\mathrm{Fe}^{2+}$.Therefore, $\mathrm{PB}$ nanorod was outstanding candidate for removal of $\mathrm{Cs}$ and $\mathrm{Sr}$ from radioactive wastewater.

\section{Acknowledgment}

This work was supported by the "13th five plan" nuclear energy development and scientific research project (the fifth batch).

Author Contributions Chuqing Yao: Data curation, Writing-original draft. Yaodong Dai: Conceptualization, Supervision, Writing - review \& editing. Shuquan Chang: Writing - review\& 
editing. Haiqian Zhang: Writing - review \& editing

Data Availability Data sharing not applicable to this article as no datasets were generated or analyzed during the current study

\section{Declaration}

Conflict of interest The authors have no conficts of interest to declare that are relevant to the content of this article.

\section{Reference}

1. Wu X, Cao M, Hu C, He X (2005) Sonochemical Synthesis of Prussian Blue Nanocubes from a Single-Source Precursor. Crystal Growth \& Design 6 (1):26-28. doi:10.1021/cg050371x

2. Vaucher S, Li M, Mann S (2000) Synthesis of Prussian Blue Nanoparticles and Nanocrystal Superlattices in Reverse Microemulsions. 39 (10):1793-1796. doi:https://doi.org/10.1002/(SICI)1521-3773(20000515)39:10<1793::AID-

ANIE1793>3.0.CO;2-Y

3. Hu L, Mei JY, Chen QW, Zhang P, Yan N (2011) Magnetically separable Prussian blue analogue $\mathrm{Mn}_{3}\left[\mathrm{Co}(\mathrm{CN})_{6}\right]_{2} \cdot \mathrm{nH}_{2} \mathrm{O}$ porous nanocubes as excellent absorbents for heavy metal ions. Nanoscale 3 (10):4270-4274. doi:10.1039/c1nr10506j

4. Bu F-X, Hu M, Zhang W, Meng Q, Xu L, Jiang D-M, Jiang J-S (2015) Threedimensional hierarchical Prussian blue composed of ultrathin nanosheets: enhanced hetero-catalytic and adsorption properties. Chemical Communications 51 (99):1756817571. doi:10.1039/C5CC06281K

5. Hu M, Belik AA, Imura M, Yamauchi Y (2013) Tailored design of multiple nanoarchitectures in metal-cyanide hybrid coordination polymers. J Am Chem Soc 135 (1):384-391. doi:10.1021/ja3096703

6. Hu M, Belik AA, Imura M, Mibu K, Tsujimoto Y, Yamauchi Y (2012) Synthesis of Superparamagnetic Nanoporous Iron Oxide Particles with Hollow Interiors by Using Prussian Blue Coordination Polymers. Chemistry of Materials 24 (14):2698-2707. doi:10.1021/cm300615s

7. Cai D, Liu B, Wang D, Wang L, Liu Y, Qu B, Duan X, Li Q, Wang T (2016) Rational synthesis of metal-organic framework composites, hollow structures and their derived porous mixed metal oxide hollow structures. Journal of Materials Chemistry A 4 (1):183-192. doi:10.1039/c5ta07085f

8. Tiwari JN, Tiwari RN, Kim KS (2012) Zero-dimensional, one-dimensional, twodimensional and three-dimensional nanostructured materials for advanced electrochemical energy devices. Progress in Materials Science 57 (4):724-803. doi:10.1016/j.pmatsci.2011.08.003

9. Zhou P, Xue D, Luo H, Chen X (2002) Fabrication, Structure, and Magnetic Properties of Highly Ordered Prussian Blue Nanowire Arrays. Nano Letters 2 (8):845847. doi:10.1021/n10256154

10. Yin X, Li H, Wang H, Zhang Z, Yuan R, Lu J, Song Q, Wang JG, Zhang L, Fu Q 
(2018) Self-Templating Synthesis of Cobalt Hexacyanoferrate Hollow Structures with Superior Performance for Na-Ion Hybrid Supercapacitors. ACS Appl Mater Interfaces 10 (35):29496-29504. doi:10.1021/acsami.8b08455

11. Xu D, Liu Z, Liang J, Qian Y (2005) Solvothermal synthesis of CdS nanowires in a mixed solvent of ethylenediamine and dodecanethiol. J Phys Chem B 109 (30):1434414349. doi:10.1021/jp051980i

12. Falyouna O, Eljamal O, Maamoun I, Tahara A, Sugihara Y (2020) Magnetic zeolite synthesis for efficient removal of cesium in a lab-scale continuous treatment system. J Colloid Interface Sci 571:66-79. doi:10.1016/j.jcis.2020.03.028

13. Feng Y, Wang X, Dong P, Li J, Feng L, Huang J, Cao L, Feng L, Kajiyoshi K, Wang C (2019) Boosting the activity of Prussian-blue analogue as efficient electrocatalyst for water and urea oxidation. Sci Rep 9 (1):15965. doi:10.1038/s41598-019-52412-1

14. Andrew Lin K-Y, Yang H, Lee W-D (2015) Enhanced removal of diclofenac from water using a zeolitic imidazole framework functionalized with cetyltrimethylammonium bromide (CTAB). RSC Advances 5 (99):81330-81340. doi:10.1039/c5ra08189k

15. Kim DS, Zakaria MB, Park M-S, Alowasheeir A, Alshehri SM, Yamauchi Y, Kim H (2017) Dual-textured Prussian Blue nanocubes as sodium ion storage materials. Electrochimica Acta 240:300-306. doi:10.1016/j.electacta.2017.04.054

16. Liu Y, Qiao Y, Zhang W, Li Z, Ji X, Miao L, Yuan L, Hu X, Huang Y (2015) Sodium storage in Na-rich $\mathrm{Na}_{x} \mathrm{FeFe}(\mathrm{CN})_{6}$ nanocubes. Nano Energy 12:386-393. doi:10.1016/j.nanoen.2015.01.012

17. Xiong Y, Cai H, Wiley BJ, Wang J, Kim MJ, Xia Y (2007) Synthesis and mechanistic study of palladium nanobars and nanorods. J Am Chem Soc 129 (12):36653675. doi:10.1021/ja0688023

18. Xiong Y, Xia Y (2007) Shape-Controlled Synthesis of Metal Nanostructures: The Case of Palladium. Advanced Materials $19 \quad$ (20):3385-3391. doi:10.1002/adma.200701301

19. Demirbas E, Dizge N, Sulak MT, Kobya M (2009) Adsorption kinetics and equilibrium of copper from aqueous solutions using hazelnut shell activated carbon. Chemical Engineering Journal 148 (2-3):480-487. doi:10.1016/j.cej.2008.09.027

20. Ahrouch M, Gatica JM, Draoui K, Bellido D, Vidal H (2019) Lead removal from aqueous solution by means of integral natural clays honeycomb monoliths. J Hazard Mater 365:519-530. doi:10.1016/j.jhazmat.2018.11.037

21. Gupta K, Yuan B, Chen C, Varnakavi N, Fu M-L (2019) $\mathrm{K}_{2 \mathrm{x}} \mathrm{Mn}_{\mathrm{x}} \mathrm{Sn}_{3-\mathrm{x}} \mathrm{S}_{6}(\mathrm{x}=0.5-$ $0.95)$ (KMS-1) immobilized on the reduced graphene oxide as KMS-1/r-GO aerogel to effectively remove $\mathrm{Cs}^{+}$and $\mathrm{Sr}^{2+}$ from aqueous solution. Chemical Engineering Journal 369:803-812. doi:10.1016/j.cej.2019.03.109

22. Ji C, Ren Y, Yu H, Hua M, Lv L, Zhang W (2022) Highly efficient and selective $\mathrm{Hg}$ (II) removal from water by thiol-functionalized MOF-808: Kinetic and mechanism study. Chemical Engineering Journal 430. doi:10.1016/j.cej.2021.132960

23. Jin Y, Liu F, Tong M, Hou Y (2012) Removal of arsenate by cetyltrimethylammonium bromide modified magnetic nanoparticles. J Hazard Mater 227-228:461-468. doi:10.1016/j.jhazmat.2012.05.004 
24. Cheng R, Kang M, Zhuang S, Shi L, Zheng X, Wang J (2019) Adsorption of Sr(II) from water by mercerized bacterial cellulose membrane modified with EDTA. J Hazard Mater 364:645-653. doi:10.1016/j.jhazmat.2018.10.083

25. Minitha CR, Suresh R, Maity UK, Haldorai Y, Subramaniam V, Manoravi P, Joseph M, Rajendra Kumar RT (2018) Magnetite Nanoparticle Decorated Reduced Graphene Oxide Composite as an Efficient and Recoverable Adsorbent for the Removal of Cesium and Strontium Ions. Industrial \& Engineering Chemistry Research 57 (4):12251232. doi:10.1021/acs.iecr.7b05340

26. Yang H, Sun L, Zhai J, Li H, Zhao Y, Yu H (2014) In situ controllable synthesis of magnetic Prussian blue/graphene oxide nanocomposites for removal of radioactive cesium in water. J Mater Chem A 2 (2):326-332. doi:10.1039/c3ta13548a

27. Jang S-C, Haldorai Y, Lee G-W, Hwang S-K, Han Y-K, Roh C, Huh YS (2015) Porous three-dimensional graphene foam/Prussian blue composite for efficient removal of radioactive ${ }^{137}$ Cs. Scientific Reports 5 (1):17510. doi:10.1038/srep17510

28. Sommer-Marquez A, Mansas C, Talha N, Rey C, Causse J (2016) Reinforced silica monoliths functionalised with metal hexacyanoferrates for cesium decontamination: a combination of a one-pot procedure and skeleton calcination. RSC Advances 6 (77):73475-73484. doi:10.1039/C6RA16980E

29. Liu J, Li X, Rykov AI, Fan Q, Xu W, Cong W, Jin C, Tang H, Zhu K, Ganeshraja AS, Ge R, Wang X, Wang J (2017) Zinc-modulated Fe-Co Prussian blue analogues with well-controlled morphologies for the efficient sorption of cesium. Journal of Materials Chemistry A 5 (7):3284-3292. doi:10.1039/c6ta10016c

30. Li J, Zan Y, Zhang Z, Dou M, Wang F (2020) Prussian blue nanocubes decorated on nitrogen-doped hierarchically porous carbon network for efficient sorption of radioactive cesium. J Hazard Mater 385:121568. doi:10.1016/j.jhazmat.2019.121568

31. Valsala TP, Joseph A, Sonar NL, Sonavane MS, Shah JG, Raj K, Venugopal V (2010) Separation of strontium from low level radioactive waste solutions using hydrous manganese dioxide composite materials. Journal of Nuclear Materials 404 (2):138-143. doi:https://doi.org/10.1016/j.jnucmat.2010.07.017

32. Zhang L, Wei J, Zhao X, Li F, Jiang F, Zhang M, Cheng X (2016) Removal of strontium(II) and cobalt(II) from acidic solution by manganese antimonate. Chemical Engineering Journal 302:733-743. doi:10.1016/j.cej.2016.05.040

33. Li T, He F, Dai Y (2016) Prussian blue analog caged in chitosan surface-decorated carbon nanotubes for removal cesium and strontium. Journal of Radioanalytical and Nuclear Chemistry 310 (3):1139-1145. doi:10.1007/s10967-016-4980-5

34. Liu Y (2009) Is the Free Energy Change of Adsorption Correctly Calculated? Journal of Chemical \& Engineering Data 54 (7):1981-1985. doi:10.1021/je800661q 35. Wibowo E, Rokhmat M, Sutisna, Khairurrijal, Abdullah M (2017) Reduction of seawater salinity by natural zeolite (Clinoptilolite): Adsorption isotherms, thermodynamics and kinetics. Desalination 409:146-156. doi:10.1016/j.desal.2017.01.026

36. Hu YY, Pan C, Zheng X, Hu F, Xu L, Xu G, Jian Y, Peng X (2021) Prediction and optimization of adsorption properties for $\mathrm{Cs}^{+}$on NiSiO@NiAlFe LDHs hollow spheres from aqueous solution: Kinetics, isotherms, and BBD model. J Hazard Mater 
401:123374. doi:10.1016/j.jhazmat.2020.123374

37. Zhang L, Wu HB, Xu R, Lou XW (2013) Porous Fe2O3 nanocubes derived from MOFs for highly reversible lithium storage. CrystEngComm 15 (45). doi:10.1039/c3ce40996a

38. Shi C, Ye S, Wang X, Meng F, Liu J, Yang T, Zhang W, Wei J, Ta N, Lu GQM, Hu M, Liu J (2021) Modular Construction of Prussian Blue Analog and $\mathrm{TiO}_{2}$ DualCompartment Janus Nanoreactor for Efficient Photocatalytic Water Splitting. Adv Sci (Weinh) 8 (7):2001987. doi:10.1002/advs.202001987

39. Yu XY, Feng Y, Jeon Y, Guan B, Lou XW, Paik U (2016) Formation of Ni-Co-MoS Nanoboxes with Enhanced Electrocatalytic Activity for Hydrogen Evolution. Adv Mater 28 (40):9006-9011. doi:10.1002/adma.201601188

40. Nai J, Lu Y, Yu L, Wang X, Lou XWD (2017) Formation of Ni-Fe Mixed Diselenide Nanocages as a Superior Oxygen Evolution Electrocatalyst. Adv Mater 29 (41). doi:10.1002/adma.201703870

41. Xu H, Zhao X, Yu C, Sun Y, Hui Z, Zhou R, Xue J, Dai H, Zhao Y, Wang L, Gong Y, Zhou J, An J, Chen Q, Sun G, Huang W (2020) Mechanistic insight in site-selective and anisotropic etching of prussian blue analogues toward designable complex architectures for efficient energy storage. Nanoscale 12 (20):11112-11118. doi:10.1039/d0nr02241a

42. Li WA, Li JR, Zhang B, Sun HY, Jin JC, Huang XY, Feng ML (2021) Layered Thiostannates with Distinct Arrangements of Mixed Cations for the Selective Capture of $\mathrm{Cs}^{+}, \mathrm{Sr}^{2+}$, and $\mathrm{Eu}^{3+}$ Ions. ACS Appl Mater Interfaces 13 (8):10191-10201. doi:10.1021/acsami.0c22690

43. Jang J, Lee DS (2016) Magnetic Prussian Blue Nanocomposites for Effective Cesium Removal from Aqueous Solution. Industrial \& Engineering Chemistry Research 55 (13):3852-3860. doi:10.1021/acs.iecr.6b00112

44. Ishizaki M, Akiba S, Ohtani A, Hoshi Y, Ono K, Matsuba M, Togashi T, Kananizuka K, Sakamoto M, Takahashi A, Kawamoto T, Tanaka H, Watanabe M, Arisaka M, Nankawa T, Kurihara M (2013) Proton-exchange mechanism of specific $\mathrm{Cs}^{+}$adsorption via lattice defect sites of Prussian blue filled with coordination and crystallization water molecules. Dalton Trans 42 (45):16049-16055. doi:10.1039/c3dt51637g

45. Qian J, Cai S, Yang S, Hua D (2017) A thermo-sensitive polymer network crosslinked by Prussian blue nanocrystals for cesium adsorption from aqueous solution with large capacity. J Mater Chem A 5 (42):22380-22388. doi:10.1039/c7ta08025e

46. Wang N, Ma W, Du Y, Ren Z, Han B, Zhang L, Sun B, Xu P, Han X (2019) Prussian Blue Microcrystals with Morphology Evolution as a High-Performance Photo-Fenton Catalyst for Degradation of Organic Pollutants. ACS Appl Mater Interfaces 11 (1):1174-1184. doi:10.1021/acsami.8b14987

47. Hu M, Furukawa S, Ohtani R, Sukegawa H, Nemoto Y, Reboul J, Kitagawa S, Yamauchi Y (2012) Synthesis of Prussian blue nanoparticles with a hollow interior by controlled chemical etching. Angew Chem Int Ed Engl 51 (4):984-988. doi:10.1002/anie. 201105190 